Portland State University

PDXScholar

\title{
Gender Bias and the Evaluation of Players: Voice and Gender in Narrated Gameplay Videos
}

Robin April Crowell

Portland State University

Follow this and additional works at: https://pdxscholar.library.pdx.edu/open_access_etds

Part of the Communication Technology and New Media Commons, Game Design Commons, and the Gender, Race, Sexuality, and Ethnicity in Communication Commons

Let us know how access to this document benefits you.

\section{Recommended Citation}

Crowell, Robin April, "Gender Bias and the Evaluation of Players: Voice and Gender in Narrated Gameplay Videos" (2016). Dissertations and Theses. Paper 3156.

https://doi.org/10.15760/etd.3150

This Thesis is brought to you for free and open access. It has been accepted for inclusion in Dissertations and Theses by an authorized administrator of PDXScholar. Please contact us if we can make this document more accessible: pdxscholar@pdx.edu. 
Gender Bias and the Evaluation of Players:

Voice and Gender in Narrated Gameplay Videos

by

Robin April Crowell

A thesis submitted in partial fulfillment of the requirements for the degree of

\author{
Master of Arts \\ in \\ Communication
}

Thesis Committee:

Lauren Frank, Chair

Tanya Romaniuk

Erin Spottswood

Portland State University

2016 
(C) 2016 Robin April Crowell 


\begin{abstract}
This study evaluates perception differences of male and female narrators in video game tutorials. Video games have long been considered a masculine pursuit, and because of this, women have endured unpleasant surroundings and interactions in gaming and related communities. With the proliferation of technologies like Twitch and YouTube gaming, gaming is more communicative than ever, increasing potential for problematic interactions. Recent booms in these technologies emphasize the importance of understanding how varying demographics are perceived, as these perceptions influence interactions, potentially limiting the likelihood of women and others' involvement and interest.

Involvement in technology during youth is associated with interests in science, technology, engineering, and mathematics careers_all fields with disparities in women's employment. Measures included confidence, credibility, performance, trustworthiness, and leadership ability to better understand how the integration of communicative technologies into gaming influences perceptions based on cues - in this case, specifically voice. Male narrators were hypothesized to be evaluated as more confident and credible than female narrators overall, while performance, trustworthiness, and leadership evaluations were hypothesized to be moderated by one's own gender identity. No significant differences emerged, which suggests a positive change in climate for female gamers and leaders in the industry.
\end{abstract}




\section{Dedication}

I dedicate this thesis to my husband, Timothy Dean Witte-Crowell. The support and encouragement from him during what has been the most challenging two years of my life cannot be understated. During my lowest lows and highest highs, he offered himself and sacrificed so much to ensure my success. It is for him, because of him, and with him that I have completed this thesis, and it is for him, because of him, and with him that I will continue to strive for excellence in whatever life may hurl at me next. 


\section{Acknowledgements}

I want to express my deepest gratitude for Dr. Lauren Frank for advising me during the duration of this program, encouraging me, and helping me through this process every step of the way. The time and care she took in giving valuable feedback and advice were integral to my success. Dr. Tanya Romaniuk and Dr. Erin Spottswood also offered great feedback and encouragement, helping me to integrate multiple perspectives into the body of work included in this project. Additionally, the faculty in the Portland State University Department of Communication has been an incredible resource in helping me to achieve all of the goals set out with this project and program. Finally, I would like to thank my closest friends and family for all of the venting sessions and kind words of encouragement along the way. 


\section{Table of Contents}

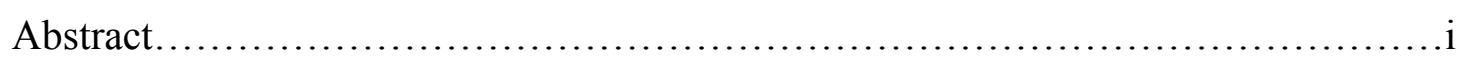

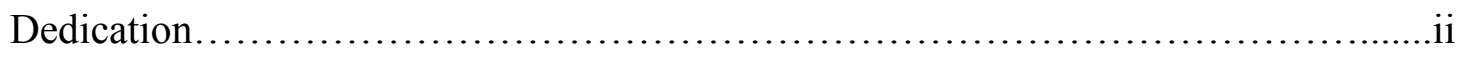

Acknowledgements...................................................ii

Chapter 1: Introduction..................................................

Chapter 2: Literature Review.............................................9

Chapter 3: Methods....................................................... 39

Chapter 4: Results.....................................................48

Chapter 5: Discussion................................................. 53

References..........................................................65

Appendices.......................................................... 71

Appendix A: Recruitment Script................................71

Appendix B: Stimulus Script..................................... 72

Appendix C: Survey Instrument.................................... 73 


\section{Chapter 1: Introduction}

Gender dynamics have been a contentious topic of conversation in the world of video gaming. Video games have been criticized over time for their less than admirable portrayals of women, and with new technology integrations by way of in-game voice chat and surrounding communities, opportunities for harassment have dramatically increased. As women gain more equal participation in video gaming, it becomes important to understand how women are perceived in video games communities and what this means for their participation in the medium as a whole. This research attempts to garner a better understanding of how women are perceived in the video gaming world.

In the past, gaming — a pastime involving people interacting with digital mediawas only seen in arcades, but in the modern digital era is made available from home consoles. Other media do not have the same affordances as gaming, as video games allow the user to closely interact with the narrative, characters, and events in a story that is told over a much more extended time than is offered with movies or television shows; for example, some games can take 12 hours to play, while other games with more extensive narratives can stretch out over hundreds of hours. In addition to close interaction with the narrative and characters in a video game story, new developments in gaming technology allow users to interact with other players via built-in communication systems directly integrated in both gaming hardware and software. Furthering communication capabilities in games, more extended affordances exist in various forms of games-related media including message boards and online forums (sites of potential 
harassment) with which users can communicate about game-specific matters. Games journalism also affords a unique interaction with the world of gaming.

\#GamerGate, a movement that was originally intended to re-ignite conversations about ethics in gaming journalism, transformed into an internet firestorm of sexism and misogyny (Chess \& Shaw, 2015). In August of 2014, independent game developer Zoe Quinn was accused of having sex with a freelance games journalist who frequently wrote for the popular gaming websites Kotaku and Rock Paper Shotgun (Dockterman, 2014). Gaming communities_-via forums on games media websites—argued that Quinn had sexual relations with the journalist in an effort to get positive reviews for her game Depression Quest, which detailed and simulated her experiences with depression in a video game format. Such accusations proved to be baseless, however, as Quinn's relationship with the journalist did not begin until long after he mentioned the game in an article. The critics also argued that the journalist Quinn reportedly slept with wrote a positive review for Depression Quest; however, neither Kotaku nor Rock Paper Shotgun actually reviewed the game, and mentioned the game only in passing.

\#GamerGaters, or participants in the \#GamerGate 'movement,' turned the conversation hostile (Chess \& Shaw, 2015; Dockterman, 2014). What was once intended as a movement to address ethics in gaming journalism turned into a fervent battleground for women working in the games industry and, in turn, female players as well. Male participants in games culture saw feminism as a threat to the games industry, and what followed highlighted the problematic gender dynamics in the world of video gaming. Anita Sarkeesian, a video blogger and outspoken critic of sexism in video game 
content itself, was thrust to the forefront of \#GamerGate, facing a multitude of rape threats, threats of violence, and a host of internet flaming. The threats went so far as requiring her to cancel a public speaking event. Sarkeesian intended to highlight her work and criticism of problematic gender dynamics in gaming at a Utah university but to protect her own safety was forced to cancel the event, as a man threatened gun violence at the school if her presentation was to happen.

Since the \#GamerGate fiasco has highlighted issues of sexism and a perceived male majority in tech-centric entertainment and media, it has become increasingly important to understand and target the issues responsible for the growing divide (or perception of) in gaming's culture and participation base. Acknowledging and understanding this divide and the perception that masculinity itself is under threat and attack could reveal better understanding of how and why these divides are present, and enlighten game developers, publishers, and communities as to how they can provide a more inclusive environment for all.

Gaming, a hobby and pastime long seen as primarily dominated by men, has seemingly excluded women since its inception as a dominating entertainment medium (Lofgren, 2015). Gaming has been a growing and burgeoning field of interest; starting from the arcades in the 1970s and 1980s, through the popularity of home consoles in the 1990s, and now in the modern digital age, $73 \%$ of all U.S. households have some type of gaming hardware in the home (Beck, Boys, Rose, \& Beck, 2012). Games are a form of communication in their own right with the integration of communication systems embedded directly into the gaming experience like Xbox Live and the PlayStation 
Network. Gaming is no longer a solitary activity, but has an interactive life. Interest in gaming tends to start at an early age, and because gaming tends not to be inclusive of all demographics (women and girls especially), this demographic is met with difficulty in not only getting involved in gaming and associated communities, but also in navigating those communities post-involvement due to the overwhelming hostility toward women, which permeates gaming and gaming related communities (Jenson \& de Castell, 2011).

The most recent available data from 2015 detailing gaming demographics in the U.S. reveals that $48 \%$ of gamers are female; however, the medium is still perceived to be dominated by men, as in the past video games have been exclusively marketed toward them (Lofgren, 2015). Additionally, the age of gamers breaches a wide spectrum with only $29 \%$ of gamers under 18 years of age, the average age of a gamer is 31 , and $26 \%$ of gamers are above the age of 50 (Beck et al., 2012; Lofgren, 2015). With these statistics in mind, the less than welcoming environment that women experience cannot be written off as mere schoolyard bullying, but must be understood as part of a larger systemic issue within games communities.

As the game industry continues to grow and expand, so too does game content which features the objectification of women and violence toward them (Beck et al., 2012). While many current games released after this study was done are seemingly combatting the prevalence of content hostile to women, the fact remains that a large library of video games do feature content that depicts women negatively. Previous content analyses of video game content found that in $41 \%$ of games with character-driven narratives, female characters were absent altogether. Further, 28\% of such games 
depicted women as objects of sexual desire, and $21 \%$ of games with character-driven narratives portrayed violence toward women. For example, in Grand Theft Auto V, the player does not have the option of playing the game with a female avatar as the three main characters are male. Additionally, women in the Grand Theft Auto series are depicted more often than not as strippers or prostitutes who the player can choose to accept their services or eliminate altogether via in-game violence. Mundorf, Dholakia, Westin, and Browness (1992) argued that an inherent male bias in technology exists that extends past gaming specifically, as men hold the majority of employment in technologyrelated careers. As is seen in examining the \#GamerGate controversy, many facets of gaming — not just content itself—are unwelcoming to women, a point that will be elaborated later in this review.

The hostile tendencies of the gaming community pose a problem for women and girls wishing to get involved with the medium. For example, an interest in gaming during childhood has been associated with an interest in careers in fields relating to science, technology, engineering, and mathematics (STEM; Cruea \& Park, 2012). Since those interested in gaming at an early age tend to be boys, girls are disadvantaged in seeking out such careers. For example, many computer science departments at universities have reported that less than $10 \%$ of their undergraduate students are women, and Cruea and Park (2012) attribute this to excessive violence toward women in video games and an overall lack of representation in games, which effectively drives women out of these sorts of interests. Because of the hostile environment toward women in video game environments — not only socially and in games media, but in actual game 
content, women are prescribed limited roles that typically revolve around an interest of sexual desire — an interest at an early age in technology can be turned off, as they feel they are not welcome or have limited roles in this emerging, evolving, and ever prevalent entertainment technology. Many games do not even offer the option to create and customize a female avatar (e.g. Grand Theft Auto V, The Witcher 3: Wild Hunt), removing the opportunity for a female protagonist controlled by the player, which may alienate women from playing as this is a stark lack of representation.

While there is not much of a gender gap in gameplay itself, there is certainly a gap in acceptance of women's participation within game communities. Such a gap poses an interesting problem considering the evolution and the current state of gaming technology and communities. Twitch (and now YouTube Gaming) are popular technological innovations in gaming and proliferate in gaming culture. Twitch allows users to livestream the video games they are playing, with the inclusion of voice-over narration, video commentary, or both. Available from consoles at home, Twitch and YouTube gaming make it possible for anybody to livestream their video game play, and viewers are able to chime in and comment via a text box on the right side of the Twitch interface. Additionally, players often create video segments that detail the steps that the player must take to effectively achieve an in-game goal, often referred to as game tutorials or 'let's play' videos. These are essentially instructional videos designed to easily guide the player from point A to point $\mathrm{B}$, and almost always include some voiceover element for the ease of the viewer. 
Previous research suggests that voice has an impact on how perceptions of credibility, proficiency, skill in leadership, and trustworthiness are developed (Armstrong \& McAdams, 2009; Eagly \& Carli, 2003; Hall \& Braunwald, 1981; Sellnow \& Treinen, 2004), a point that will be elaborated in Chapter 2. More particularly, the gender of the voice can impact all of these factors. Because Twitch is a growing staple in the gaming community and culture, it is increasingly important to understand the impact of voice within these environments, and more specifically_how the gendering of voices featured in gaming livestreams and instructional videos affects how players are perceived in these videos.

This study seeks to extend the current knowledge of the impact of voice-over narration in the context of gaming culture. Through the lens of schema theory, it will outline gender dynamics in gaming communities, review previous studies of voice and gender, and examine what their findings mean for women in leadership roles within gaming communities and cultures. Through an experimental design testing the effects of voice on viewer perceptions of confidence, credibility, performance, trustworthiness, and leadership ability of the players featured in gameplay videos and tutorials, this study seeks to discover how voices and gender cues impact perceptions of gameplay video viewers.

Relevant theoretical considerations regarding schema theory will highlight the discussion of gender and its interplay in games communities, along with the hypotheses that will guide this study. Chapter 2 will present a review of literature to provide a nuanced look into the environment that women face as participants in gaming culture by 
highlighting several instances in which women have been marginalized in gaming environments, both in games and outside of them. Chapter 3 will detail the methods employed in this research, including the scales used to measure the aforementioned constructs, the participants involved in the current study, and types of demographic information collected to paint a broader picture of the sample. Chapter 4 will report the results of the research with relevant statistical analyses, demographic information, and exclusionary criteria used to determine an appropriate sample, and Chapter 5 will discuss these results along with limitations and areas for future research. 


\section{Chapter 2: Literature Review}

This chapter will define relevant terms, and most specifically will provide a concrete understanding of what is meant by gender, sex, masculinity, and femininity. Then, it will discuss the theoretical framework for this study—schema theory — and outline the implications that schema theory has on this research, as well as different relevant schemata under the umbrella of schema theory proper. Then, the relevant literature relating to women in gaming environments will be discussed at length, providing the overall lens of this study in relation to gender and video gaming. Additionally, effects of voice and perceptions of speakers will be detailed in terms of gender and associated schemata.

\section{Gender, Sex, Masculinity, and Femininity}

Any discussion of gender and biological sex benefits from first having a detailed understanding of what is meant by these terms. Both gender and biological sex have been broadly examined in the context of communication research, and both have unique meanings and implications that aid in developing an understanding of gender politics in video gaming.

Sex is assigned at birth as a biological category that considers physical anatomy, psychology, and hormones (West \& Zimmerman, 1987). Conversely, gender is a status that an individual arrives at that is a construction of biological sex, achieved through societal, cultural, and psychological means all based on one's biological sex (West \& Zimmerman, 1987). In the past, roles in culture, family, and professional life were seemingly assigned based on biological sex, but actually arise out of socialized norms ascribed to biological sex which in actuality calls to gender socialization (West \& 
Zimmerman, 1987). So, gender serves as a structural component of identity that situates individuals into roles prescribed to men and women as appropriate or inappropriate. Because of role associations based on what is deemed culturally appropriate for men and women, cultural assumptions dictate what is considered normative in terms of one's gender, and behaviors are linked to traditional conceptions of men and women. Such assumptions are also called trait-based assumptions, which calls to Bem's (1981) conception of sex-typing based on one's visible gender. Sex-typing, then, relies on individuals' preconceived notions about what behaviors and interests are appropriate for men and women based on socialized gender norms (Bem, 1981; West \& Zimmerman, 1987). Gender is a binary that is socially constructed, and serves to classify individuals as either strictly male or strictly female (Schippers, 2007). While gender socialization to male and female binaries is still prevalent, there have been major shifts and strides more broadly since Schippers' (2007) study was published.

Masculinity and femininity. As an individual's gender is a socially constructed identity, it is important to understand how such identities are constructed in terms of what these culturally available assumptions about masculinity and femininity are. Schippers (2007) provided a breakdown of masculinity, femininity, and gender hegemony that will be used for the purposes of the current study. Schippers (2007) proposed three primary components that serve as the make-up for the concept of masculinity; 1) masculinity is a socially located identity that individuals can claim through social practices; 2) individual characteristics and behaviors that have been culturally coded as masculine; and 3) when men (or women) embody practices that are coded masculine, broad cultural effects ensue. 
Thus, performing masculinity has great impacts on how individuals moving into this social space experience not only the self and their own bodies, but also how that self is projected and communicated to other people. The very performance of masculine-coded behaviors and identity construct what is coded as masculine when other individuals perceive these behaviors. For example, Schippers (2007) identified authority as an attribute that is typically coded as masculine, and subordination as an attribute that is typically coded as feminine- though masculinity and femininity are certainly not limited to these attributes and these attributes alone. To summarize, then, masculinity embodies the positions that are socially constructed to belong to men, practices that are culturally viewed to be traditionally performed by men, the effects of the collective performance of these practices on a broad, cultural scale, and pertains to relations held globally that serve to dominate (Schippers, 2007).

The concept of femininity, then, is in direct contrast to masculinity. As masculinity is considered a position of dominance, femininity is considered a position of subordination (Schippers, 2007). While this may not be the case worldwide, American culture codes femininity as such. Where masculinity is associated with strength and dominance, femininity is ideologically associated with submissiveness; "femininity includes physical vulnerability, an inability to use violence effectively, and compliance" (Schippers, 2007, p. 91). Masculinity and femininity contrast each other, and the concept of gender hegemony serves to subordinate femininity in favor of masculinity.

Gender hegemony. Gender hegemony, as a construct, refers to the subordination of femininity and alternative masculinities that are not considered traditional (as in 
masculinities held by gay men; Schippers, 2007). Hegemonic femininities are not as broadly examined as hegemonic masculinities, but multiple conceptions of femininity exist. Hegemonic masculinity can embody the use of forceful interpersonal violence, authority, and physical strength, while femininity is in direct contrast to this (physical weakness, non-violence, compliance; Shippers, 2007). These definitions benefit gender hegemony as a whole by symbolically subordinating women in service of hegemonic male dominance. These meanings and rationale for male dominance provide frameworks for how individuals conduct themselves socially and culturally, as if permission to enact male dominance has been culturally granted. In the culture of video games, hegemonic masculinity serves as an excuse to subordinate and dominate women engaging in the medium, and individual schemata for what constitutes masculinity and femininity could be a factor influencing how women are treated while participating in certain types of social gaming.

\section{Schema Theory}

A schema is a series of connotations that organize an individual's perceptions and thoughts about the world and the people in it (Bem, 1981). Schema theory, "construes perception as a constructive process wherein what is perceived is a product of the interaction between the incoming information and the perceiver's preexisting schema" (Bem, 1981, p. 355). So, schema theory posits that the individual receiver of a stimulus or information will process that information based on the receiver's existing socially constructed perceptions or stereotypes. In a study about how gender and race are depicted in election coverage, Major and Coleman (2008) wrote that schema theory is 
used to explain how gender and racial stereotyping happens. They found that women were more often covered in local media in terms of their gender roles (like motherhood and family roles) than men were.

These findings, they argue, are largely based on pre-formed schemata that journalists themselves had (Major \& Coleman, 2008). Schemata are created by people in an effort to organize and categorize new information. Further, the authors suggest that schemata function as cognitive structures that work to organize knowledge or certain concepts based on previous experience. With that said, schemata are not always bad. They can be used to organize and categorize new information that may seem overwhelming if previous referents are not already in place (e.g. starting classes at a new school). An individual may have previous information stored that may help them adapt to the new situations. Although the individual may not be familiar with that school specifically, they are familiar with schools in general and can thus formulate expectations for the new school based on previous experiences. Forming what the authors call person schemata, however, is where schema processing becomes problematic.

Person schemata are used to categorize information about people, and such categorizations can be based on factors such as race or gender (Major \& Coleman, 2008). When race or gender are at the forefront of an individual's schematic processing, heuristically jumping to stereotypes can happen without the receiver of information realizing it, which can be harmful in assessing perceptions of others. Heuristics, more specifically the availability heuristic, seem to be one of the functions at the heart of schema processing and shed light on how gendered biases become so common. 
Tversky and Kahneman (1974) said that the availability heuristic is called upon when some things enter the mind more easily than others. Relying on such shortcuts could lead to predictable biases. Additionally, more recent encounters that are easy to recall, or in more recent memory, are more available than older information; so when availability is employed, it is those more recent memories that are recalled and have the potential to cause false correlations in the mind. Thus, schema processing comes into play when certain things are associated with a specific gender category — as in video games and their association with masculinity - and available stereotypes can cause underlying biases about that gender when the schema does not fit.

Existing within the boundaries of schema theory are several sub-schemata by which individuals judge their day to day interactions, and for the purposes of this research, two different schemata will be highlighted. Gender schema theory exists under the umbrella of schema theory but it interacts also with the perceiver's gender-not biological sex - and the gender of the perceived.

Gender is a social construction of biological sex-related attributes - the norms associated with an individual's biological sex including dress, demeanor, and conduct in social life (Westerwick \& Hoplamazian, 2012). Men and women are socialized differently depending on related gender norms, as was mentioned in terms of masculinity, femininity, and gender hegemony (Schippers, 2007; West \& Zimmerman, 1987). Such socialization creates schemata by which individuals process incoming information, in this case, socialization based on an individual's gender and the gendering of incoming information. This gender schema sub-theory posits that gender dictates the perceiver's 
preexisting schemata, and incoming information is processed on the basis of sex-typing, in which individuals fit closely within the confines of what society qualifies as masculine or feminine (Bem, 1981). Thus, schemata are formed based on individual conceptions of gender, impacting how information is processed. For example, someone might sex-type a male as competitive, physically big, technologically savvy, and eager to prove it while women may be sex-typed as technologically ignorant, compassionate, caring, physically small, and docile (Halbertsam, 2002; Kimmel, 2004). All of these factors can work together to produce individual schemata based solely on an individual's perceived gender, which a user might closely identify with that person's biological sex.

Effects of schema. Because of the gender schemata that people can form, certain topics become gendered as either male or female (Linek, Gerjets, \& Scheiter, 2010). For example, Linek and colleagues (2010) found that females are typically seen as more qualified to discuss topics like relationships and love, while men are seen as being more qualified to discuss matters related to computer science and mathematics because these topics are gendered feminine and masculine, respectively. Their experiment involved both men and women delivering different types of information, for example, about math and science or about love and relationships, then asking the participants to evaluate their perceptions of the ability for the speaker to effectively convey such information (Linek et al., 2010). Linek and colleagues (2010) found that this influenced how credible the participants thought the information was, and how confident the speaker was in relaying the information - they attribute their results to preexisting schemata held by the receivers of the provided information. 
Knobloch-Westerwick and Hoplamazian (2012) looked at whether or not an individual's self-concept of gender (how masculine or feminine they perceive themselves to be) or biological sex had an impact on whether or not they would read sex-typed magazines, or magazines associated with a particular gender. They found that gendermore so than biological sex-significantly impacted which magazines the participants would select, with men gravitating toward magazines about male-oriented topics, and women choosing magazines more closely associated with stereotypically feminine gendered topics. This suggests that certain people may have a preference for media content that more closely aligns with their gender, which is problematic in gaming as women are underrepresented or depicted as sexual objects or victims, and gaming is a masculine-coded pastime. This, too, says that sex-typed individuals are unlikely to deviate from activities that do not align with what is considered normatively masculine or feminine. People work to fit their own gender schema and typically do not deviate from it—a perpetuating cycle (Bem, 1981; Linek et al., 2010; Westerwick \& Hoplamazian, 2012).

In addition to gender schema, the heterosexuality subschema rests on the supposition that heterosexuality is the norm, and deviations from that norm break existing schemata (Bem, 1981). The heterosexuality subschema reiterates the notion of inherent difference between men and women, as heterosexuality is itself perpetuated and considered normative based on gendered differences, a concept that gender scholars call heteronormativity (Pulos, 2013). Interestingly, in a critical discourse analysis of conversations in the World of Warcraft universe (a game which will be elaborated more 
in depth later in this review), Pulos (2013) found that overall, hegemonic masculinity and feminine stereotypes — including hypersexual representations — run rampant, further characterizing video games as masculine-oriented and heteronormative. This aligns with the previous discussion of how some topics are gendered masculine or feminine, and discussions of these topics break the gender schema when coming from sources that do not align with previous conceptions of who may be qualified to discuss that topic. Thus, the argument arises that the heterosexuality subschema contributes to a hostile environment for women in the gaming community, as women participating and discussing gaming break preexisting schemata that reflect gaming as a masculine pastime. Because masculinity is considered the norm in video gaming, gender hegemony in this world serves to continuously subordinate women in the gaming community in favor of male dominance (Shippers, 2007; West \& Zimmerman, 1987).

Next the discussion turns to the tumultuous and contentious gender dynamics within gaming. Based on these examinations of the gender schema, the question arises of how differently the confidence, credibility, performance, trustworthiness, and leadership ability of female narrators of instructional gameplay videos will be evaluated in comparison to male narrators of the same videos.

\section{Gender, Gaming, and Intersectionality}

In the gaming world, problems arise for female gamers broadcasting their gameplay and instructional videos, as they are treated as less qualified to discuss gamingrelated matters. Many examples that will be later discussed reflect this imbalance. Gaming fits comfortably within the world of computers and technology, which are topics 
typically gendered male under the terms of schema theory. Because gaming is perceived as predominantly male-centric, schema processing comes into play in everyday interactions in online gaming environments (Williams et al., 2009). When gender expectations are broken, people are subject to social stigma or backlash—as in men working in feminine-gendered occupations, or women with a great amount of interest in sports. Such a backlash arises when individuals break gendered expectations. Video games are seen as a predominantly male pursuit, and an increase in women turning to the medium indicates a changing landscape; however, gameplay for women would be breaking pre-established stereotypes as the technology has been historically in itself gendered masculine.

To coincide with the gender schema, Royse, Lee, Undrahbuyan, Hopson, and Consalvo (2007) add the Foucauldian concept of technologies of the gendered self, which posits that some technologies are in themselves gendered. The researchers make the case for the telephone as a technology that is gendered feminine; it became gendered feminine by depictions in mass media of women and girls pictured frequently talking on phones. Importantly, the telephone became gendered because of media depictions, not simply because of the technology use in everyday life. The researchers argue that although technologies like gaming are typically gendered, research can navigate the various ways that men and women negotiate their identities relating to modern technology (Royse et al., 2007; Williams et al., 2009). Thus, the idea of technologies of the gendered self provides researchers a way to understand differential play patterns and interests among women (and men), and it gives us a more useful theoretical tool for understanding how women negotiate 
particular technologies and how their various work of negotiation can produce different results and different interpretations of the consumption of technology as a gendered practice. (Royse et al., 2007, p. 561)

While \#GamerGate might be the most visible controversy surrounding women and gaming in recent memory, this is far from the first instance of contentious gender dynamics in gaming communities (Chess \& Shaw, 2015). Mundorf and colleagues (1992) contend that a gender bias is prevalent in new technology, even as gaming was emerging as a new and more accessible entertainment medium in the early 1990s. They argue that there is an inherent male bias in the content of video games, which likely deters women from an interest in the medium. In their study, they wanted to find out what the patterns of familiarity between men and women were with certain technologies, including information technologies and entertainment technologies. Their findings concluded that men, across the board, showed greater intent to use technology, including home entertainment technologies and state of the art technologies (Mundorf et al., 1992).

Women in the study, however, had greater interest in communication technologies (Mundorf et al., 1992). Because media platforms like Twitch and YouTube gaming combine entertainment technologies with communication technologies, and gamers combine these technologies with preexisting practices; interest in gaming can now take many forms. With broad appeal for men because of the entertainment technology aspect of gaming, and for women, because of the recent integration of communication technology in everyday gaming practices, more diversity is possible in the medium's participation. The newly integrated social nature of games could be a draw for women to play, as women gravitate toward communication technologies (Williams et al., 2009). However, this social aspect does not remove the overall masculine connotations attached 
to the medium (Williams et al., 2009). If certain types of technologies are gendered feminine (communication technologies) or masculine (video gaming as a whole), and then later combined into one cohesive medium as the integration of Twitch and other social features has successfully accomplished, new problems arise with inclusion, involvement, and bias in participation in environments that are typically more hostile toward one gender than the other, as per the performance of hegemonic masculinity in online gaming culture (Royse et al., 2007; Schippers, 2007).

The gender divide is not simply perpetuated by people, however. Even game content itself can alienate women. If women raise issues with game content that they see as sexist, the resulting backlash from gaming communities can further deter the involvement of women in games. Further, Beck and colleagues (2012) found that violent content toward women in video games increased rape-supportive attitudes in male players. Because schemata are formed based on previous experience, being exposed to content in games that feature women depicted as objects or victims can influence how women are perceived outside of an in-game context. Building on this, some research reiterates the gender divide in gaming in both the past and present, which lends to a contentious environment for female gamers and enthusiasts.

As for one example, World of Warcraft $(W o W)$, a popular massively multiplayer online role-playing game (MMORPG), has been the host of controversy surrounding women and gaming in recent years (Braithwaite, 2013). The WoW forums overlap with the in-game community, allowing for players to communicate about in-game happenings, expansions, and gaming generally. In MMORPGs like $W o W$, content expansions occur 
on a regular basis in an effort to keep the existing game fresh and to keep long-time players coming back and returning to the game world. Before the launch of a recent content expansion, the $W o W$ developers invited select players to participate in a beta test of the upcoming content. While participation in the forums was limited to those who were beta testing the content expansion, anyone on the internet could see what people were posting in the discussions.

Ji Firepaw, an integral quest-giving character in a $W o W$ content expansion, became the epicenter of a heated debate in these forums. This non-playable character was responsible for giving new quests and missions to players in the $W o W$ universe. Ji Firepaw spoke differently to male and female avatars (the player-created character that the player experiences the game world through), doting on men as 'strong' and reducing female avatars down to their appearances by calling them 'gorgeous' and 'unable to keep men away' (Braithwaite, 2013). A female blogger and participant in the $W o W$ forums for this content expansion became vocal about the different ways that Ji Firepaw communicated to male and female avatars, noting that it came off as 'creepy' and questioned the observable biased representations and treatment based on gender (why female avatars were reduced to their appearance while male avatars were doted on for their strength). The comment was picked up by a $W o W$ newsletter as a way to start the conversation about in-game gender inequity. The dialogue of Ji Firepaw was eventually changed based on these critiques to greet female avatars as being poised and confident, and this change resulted in massive dissent from the WoW community on not only the 
developer's website, but on other forums, blogs, and gaming websites (Braithwaite, 2013).

Braithwaite (2013) employed feminist theory and critical discourse analysis to explore the negotiation of power in virtual environments as well as to analyze how the discussions surrounding Ji Firepaw were undertaken. Additionally, Braithwaite (2013) looked for emergent patterns that would help explain the culture and norms through which the conversations emerged. Her research introduced the notion that gaming and gender are intersectional, meaning that gender outside of the game is performed online and that individual identities surrounding gender and identities as a gamer intersect to introduce a unique dichotomy in online gaming. Further, female interest in gamesdespite a growing female player base — is still often viewed as "trespassing" by male gamers, further perpetuating hegemonic masculinity in online gaming (Braithwaite, 2013, p. 707; Schippers, 2007). As gaming is gendered masculine, female interest-since it does not align with traditional conceptions of femininity - is commonly seen as breaking gender norms by simple participation, and is often interpreted as a transgression regarding a stereotypically male-oriented domain. In a discussion about female masculinity, Halbertsam (2002) wrote that tomboys (girls or women who have interests associated with masculinity) are generally accepted when the girl still has a strong sense linking her "tomboyism" to her female identity, but punished when the link to male identity gets too close and extends past childhood into adolescence. Thus, the gamer identity — which is linked closely to masculinity — is an identity that women are often met with backlash for holding, as their presence in the medium is seen as incompatible with 
the masculine gendered domain of gaming and traditional expectations of "appropriate" femininity beyond adolescence (i.e. in adulthood; Braithwaite, 2013; Halbertsam, 2002).

Brathwaite's study revealed several findings that seem reflective of the gaming environment and attitudes toward women. First, there was a perception of feminists in the $W o W$ forums as 'killjoys' who ruined all of the 'fun.' By calling feminists the problem in these forums - and by extension, in the gaming community - the logical response by many in the discussion would be to remove them from the conversation altogether. Additionally, the changes to the dialogue of Ji Firepaw were seen as a threat to hegemonic masculinity, lending further credence to Bem's (1981) consideration of the heterosexual subschema, and reiterating gender hegemony that subordinates women in online gaming communities (Schippers, 2007; West \& Zimmerman, 1987).

Further, those that critiqued Ji Firepaw's speech patterns were met with comments essentially telling feminists to quit playing — either deal with inequality, or get out. A couple of examples that Braithwaite (2013) highlights are as follows:

Its people like you that ruin the world for the rest of us. You literally cried until a good character was gutted because YOU didnt like the character. You imposed YOUR sensibilities on others and subjected the rest of us to your overly sensitive nature. So for all of us we now have a LESS enjoyable experience, a less enriched experience full of diverse characters, all because YOU got your panties in a bunch because an NPC [non-player character] called you pretty. You ruin GOOD things for the rest of us, and you should be ashamed of yourself. [Macey, \{Feedback\} Ji Firepaw, 2012: 481] (p. 6).

Another comment read as follows:

There is a REAL war on women and their rights happening RIGHT NOW in the United States that you can focus your energies on if you are truly concerned about gender equality. [Caz in Myers, 2012] (p. 6). 
This presents an overlap between lived and virtual experiences, in that virtual worlds depend on lived worlds to maintain existence even if norms rooted in reality meander into virtual worlds - neither live in a vacuum (Braithwaite, 2013). These findings suggest that gender politics are not contained solely in just one dimension of gamer life- they bleed through the walls and exist within and outside of virtual spaces, creating contentious situations in which women have to tread carefully in the face of threats and bullying when trying to expose gender inequality in gaming environments and communities.

Thus, gamers bring their real-world identities into game worlds and vice-versa, drawing on conceptions of masculinity and femininity to dictate interactions and schemata in gaming contexts. Due to the intersectional nature of the gamer identity and offline identities, individuals will draw on gender schemata when evaluating others' gameplay performances and instructional ability, bringing both gender identity and whether or not the individual identifies as a gamer into their evaluations of other players. An individual's gender identity may be a driving force behind evaluations of other players and their performance in the game environment.

Women in gaming publics. In addition to games content and the male gendering of games culture, games media can also cause women to feel like outliers in a community that is seemingly against them. While game content can alienate women and prescribe limited roles in the game world, the media surrounding the culture of gaming has also been less than welcoming. Sexist depictions of women in games media have also been called out, but receive much the same responses as when games themselves are critiqued 
(Beck et al., 2012; Braithwaite, 2013). In the world of games, it would seem that women and girls must walk a tight path.

One example that speaks to this issue involves Penny Arcade, a popular web comic that focuses on geek humor and gaming culture. It was the epicenter of a wave of controversy in recent years due to a comic strip that many women in the gaming community found to be in poor taste (Salter \& Blodgett, 2012). In the first panel of the comic strip, a man in tattered clothing holding a pickaxe is pictured, presumably enslaved by an antagonist to the comic's story. Next to him is a large cartoon wolf with large muscles pictured whistling tunes, while the enslaved man asks for the wolf-depicted here as a hero of sorts - to release him from the 'unending' hell that he is enduring (Krahulik \& Holkins, 2010). The next panel is a close up of the slave, describing the torture that he and his fellow captives endure nightly, and more specifically that "every night, we are raped to sleep by the dickwolves" (Krahulik \& Holkins, 2010). The third and final panel features an exchange between the slave and the hero wolf figure, in which the wolf says "I only needed to save five slaves. Alright? Quest complete" (Krahulik \& Holkins, 2010). The joke is a play on common morality mechanics in RPG games, in which the hero of the story is charged with rescuing characters in peril, but only enough so that the quest requirements are satisfied.

This joke in particular caught the attention of a blogger for a feminist website, who reported on the issue - claiming that it perpetuated rape culture in video games - and received criticism from the gaming community and the authors of the comic itself. The authors dismissed those who took offense as being overly sensitive, and responded with a 
comic making fun of those who had negative reactions to the 'Dickwolves' comic, the point of original contention. Penny Arcade further fueled the fire by selling 'Dickwolves' shirts in their webstore.

While the 'Dickwolves' incident serves as the locus of interest for Salter and Blodgett's (2012) study, broader themes including the emphasis on hypermasculinity and larger issues about the role of women in gaming communities emerged. The interconnectedness of masculinity and hardcore gaming cannot be ignored. Such an emphasis serves to marginalize women and decrease the visibility of them within gaming culture broadly, thus creating hostility toward women who are vocal in gaming-related interpersonal spheres. When incidents like this occur, hegemonic masculinity in video gaming is rewarded while femininity is punished. The punishing of femininity is in service to gender hegemony, and lends to the conception that video gaming is a masculine domain. The enduring association with masculinity and video gaming influences how individuals perceive the medium, potentially crafting schemata through which individuals will process information regarding gaming and the surrounding culture (Bem, 1981; Schippers, 2007; West \& Zimmerman, 1987).

Especially since women are seen to have a limited set of roles in gaming - as sex objects, victims, or invisible altogether - it becomes increasingly important to expose the gendering of technology as masculine and foster a more inclusive environment for all who want to get involved. Salter and Blodgett (2012) close out their analysis of the 'Dickwolves' scenario by noting that women gamers, simply by just participating in the medium, attempt to transgress the roles prescribed to women in gaming communities and 
as a result, are often greeted with hostility from male gamers who hold true to the hypermasculine dominance in gaming and cultures surrounding it.

Situating gender and gaming. As hypermasculinity is commonly associated with an interest in gaming by males, it is also important to understand how men and women interact with gaming. Yates and Littleton (1999) saw gender difference as a way of theorizing the different ways that men and women engage with gaming as a medium for entertainment. Through focus groups and ethnography, the researchers found that women look more for exploration, problem and puzzle solving, strategy, and planning in gaming while men seek out the more competitive interactions and action elements in the medium. Additionally, they found that in-game characters also influence how people engage with gaming and as seen with the Ji Firepaw example described by Braithwaite (2013), the way in-game characters interact with player avatars based on gender certainly has an impact too.

The intersection of gender identity and gamer identity likely comes from experiences in play too, not just interactions with other players and interactions with NPCs, but how an individual plays and meets their own performance. Part of the formulation of an identity as a gamer comes from the affordances of the games themselves, or the gamer's reactions toward in-game elements. Thornham (2008) found that women are far more likely than men to vocally put down their own gaming performances. Perhaps the stereotype that women are inherently bad at gaming, or intruding in environments to which they do not belong, comes from how they talk about their own experiences (Braithwaite, 2013). While this is no inherent fault of women 
broadly, repeated cycles of being met with negativity and harassment in gaming situations could lend to feelings of inadequacy upon failure to achieve in-game tasks. More positivity and more confidence in their own performances in video games could change how women react to their own experiences, but prevalent negativity toward women and the exclusive, hypermasculine climate surrounding them in gaming communities perpetuates poor assessments of their own skillsets when women engage with the medium.

Because women are not traditionally vocally confident in their gaming abilities as Thornham (2008) found, men are likely to be evaluated more positively overall (by both men and women). Women, then, are more likely to be evaluated negatively overall, as female participation in the medium is seen as trespassing or transgressive, and hegemonic masculinity is a dominance structure that thrives in video game content (Braithwaite, 2013; Schippers, 2007; Thornham, 2008; West \& Zimmerman, 1987). Since men are seen to be more familiar with gaming, they are likely to be viewed as more credible to discuss it, regardless of an individual participant's gender identity.

\section{Voice, Gender, the Matchup Hypothesis, and Social Agency Theory}

The discussion turns now to an exploration of research detailing gender and the voice, and how the two interact to formulate the listener's and viewer's perceptions of proficiency, credibility, and competence of the speaker. Because innovations like Twitch and YouTube Gaming are bringing both the in-game performance of video gaming and the individual level performance of gaming together in tandem to be broadcast to the world, it becomes important to navigate the different elements that go into such 
performances. What was once performed privately either in the home or in an arcade is now visible far and wide (Beck et al., 2012; Lofgren, 2015). One of the primary elements on display with media such as Twitch is the element of voice.

The matchup hypothesis. Since the purpose of many gameplay videos is to help the viewer navigate through difficult parts of the game, an important consideration is the effect of the narrator's voice on the learning ability of the viewer. The matchup hypothesis suggests that if some salient attribute renders a product and a spokesperson congruent in some way, then the source of information becomes credible based on schemata held by the receiver, as in masculinity being closely linked with video games. Linek and associates (2010) sought to test the effects of voice in the presentation of multimedia messages via a series of experiments manipulating the gender of the speaker in these messages, and in another experiment, allowing the subject to choose the voice the information would be presented with. A female speaker discussing love and relationships was considered more credible than a male speaker discussing the same topics, while male speakers were found to be perceived as more credible when talking about topics relating to mathematics or computers. Speaker gender was guessed not only on the qualities of the voice conveying the message, but also regarding the topics discussed. Similarly, Lynch and Schuler (1994) examined the matchup hypothesis in terms of advertising spokesperson schemata and product schemata. They tested this hypothesis by having participants evaluate the credibility of the spokesperson against congruence between several different products and spokespersons with similar attributes based on gender stereotypes and perceived gender differences. Using exercise equipment 
as an example, they found that the physical fitness of the spokesperson increased their perceived credibility in discussing the product. Because of the subject matter at hand, a fit speaker is more likely to be taken seriously when discussing exercise equipment over an un-fit speaker. The researchers also claim that fitness is a trait closely associated with masculinity, rendering topics themselves as gendered as well as products relating to such topics, and the credibility of the speaker discussing certain topics or products is affected based on salient, similar attributes — often determined by the gendering of products and technologies (Linek et al., 2010; Lynch \& Schuler, 1994; Royse et al., 2007).

Linek and colleagues (2010) suggest that social agency theory is a possible explanation for this phenomenon, and when considered in tandem with the gender schema, it could explain why these associations are occurring. Social agency theory, or SAT, involves five steps as outlined by the authors. First, voices and pictures can act as social cues. Second, information is processed and interpreted socially rather than simply delivered. Third, messages are interpreted as social communication which activates social conversation schemas, meaning that the established rules of social communication are then applied to the interaction mediated between humans and computers (or in this case, gaming media). Fourth, the learner assumes that speakers are trying to convey messages that are meaningful, thus the listener exerts effort in interpreting the message. And finally, deeper cognitive processing results in a more meaningful representation of the message to be conveyed.

Based on the results of their study, Linek and colleagues (2010) posit that certain information in and of itself seems to be gendered and suggest that multiple voices be used 
in the learning process to activate a broader array of social schemata. Similarly, Hall and Braunwald (1981) sought to uncover the nuances of gender in voice communication based on perceived differences of men and women. Discomfort in communication can arise based on the gender of the speaker, and whether or not topics of conversation align with the perceiver's preexisting perceptions of that gender (Hall \& Braunwald, 1981). Further, they looked for the impact of tone, pitch, and volume in perceptions of the speaker. In one of their experimental conditions, Linek et al. (2010) did not reveal the gender of the speaker, but let the judges in the study decide what they thought the gender of the speaker was, based on the qualities of the voice and the topics of discussion. When the topic of discussion was more male oriented, the judges would guess that the speaker was male - regardless of whether the speaker actually was. In this study, mathematics was a primary topic of discussion and has historically been coded as a masculine pursuit (Linek et al., 2010). Additionally, the judges were tasked with identifying the speech target of the recording. The findings indicated that gender schemas influenced who the judges would say that the recorded voices were conversationally directed. Again, when the recordings were of topics gendered male, the judges were more likely to assign a male recipient. When the topics were gendered female, the same was indicated.

Similarly, Strach, Zuber, Fowler, Ridout, and Searles (2015) found that the choice of a male or female voice in political advertisements influenced the perceived credibility of the advertisement and - as a result — the candidate's perceived credibility. Because part of the reception of a message relies not only on the message itself, but also its delivery; the researchers sought to uncover the reasons behind the choice of the gender of 
the speaker when choosing a narrator. They found that once again, it was not necessarily the gender of the speaker, but the topics being discussed that impacted perceived credibility based on whether or not the topics were gendered masculine or feminine, and what type of voice was delivering the messages - a male voice or a female voice. Strach and colleagues (2015) found that the topics discussed in political advertisements were gendered in and of themselves; topics like family and community are considered feminine and topics like foreign policy and the economy are considered more masculine, lending more credence to the notion of gender schemata as discussed by Bem (1981). When topics were gendered feminine, the advertisement was perceived to be more credible when voiced by a female speaker, and vice versa for male speakers (Strach et al., 2015).

Gender cues play a large role in both written and voice communication and what such cues mean for leadership roles and perceptions of credibility based on a person's established gender schema. In a study of the role of gender in perceived competence, Sellnow and Treinen (2004) found that in academic settings, papers believed to be authored by female writers are generally evaluated more poorly— that is, when a paper is believed to have a female author, it is critiqued more harshly. With this consideration in mind, the researchers wanted to uncover the differences in how men and women were critiqued by their peers in an academic environment. In their experimental design, students gave identical speeches to an audience of their peers in pre-recorded videos. One male and one female were chosen to give the speeches; however, three separate recordings were created for both the male and the female speaker, one in which the 
individual was dressed professionally, one in which the speaker was dressed casually, and one in which the speaker was dressed sloppily. They found that speaker sex alone did not dictate how they were evaluated by their peers, but the dress of the speaker influenced evaluations more for the female speaker than for the male speaker. Thus, sex and physical appearance influenced the types of comments that the speakers received, with a gender bias surfacing in the open-ended feedback from student evaluators.

Because Twitch and YouTube Gaming employ the use of both audio and visual cues, these findings suggest that when women are visible on screen they may be critiqued differently than men. While the current study focuses on the effects of voice and not visual cues relating to the appearance of the speaker, the notion that visual cues in addition to voice impact viewer perceptions is an important consideration for future research to build on.

In terms of online communication, Armstrong and McAdams (2009) looked at source credibility in relation to blogs, and what impact gender cues had on the reader, although voice was not evaluated for the purposes of their study. They contend that information processing is influenced commonly by cues that serve as mental shortcuts (or heuristics) to judge the source by, and such heuristics are influenced by schemas in the same vein that Bem (1981) posits. Determining the best possible matchup between the topic and the speaker based on preexisting gender schemata is important for understanding how information is received and processed (Lynch \& Schuler, 1994). Given the gendered nature of the gaming community, and that gaming is masculinegendered and considering the matchup hypothesis, I propose the following hypotheses: 
H1: A male narrator in a voiced gameplay video will be evaluated as more confident discussing gaming than a female narrator.

H2: A male narrator in a voiced gameplay video will be evaluated as more credible discussing gaming than a female narrator.

Individual identities and information processing. Drawing once again on Hall and Braunwald (1981), the receiver of the message is just as important as the deliverer regarding certain attributes. When topics are gendered feminine and delivered by a female speaker, the audience is more likely to see the message as credible and the speaker as confident in discussing the subject. When delivering messages about topics that are gendered male, a male speaker will likely be seen as a more credible and confident source for the delivery of that particular message. In terms of confidence and credibility, the identity of the receiver of information does not impact evaluations, as some topics are viewed overall as predominantly masculine or feminine. Some constructs, though, are impacted by both the identities of the message deliverer and the message receiver.

These findings also relate to gaming and game-centric communities. Williams, Caplan, and Xiong (2007) conducted a study to uncover what exactly voice adds to the gaming experience. They found that while an overall sense of community was not significantly impacted by the inclusion of voice, trust in gaming acquaintances and gaming partners was increased with the inclusion of voice. As previous communication revolved around text-based interaction, only within the last decade or so has voice been an option for communication in games. The researchers tested the effects of video games moving to voice communication from a long history of text-only communication, especially in MMOs like $W_{o} W$ (Williams et al., 2007). The inclusion of voice has 
enhanced the gaming experience, facilitating an environment where relationships can form, and social bonding is increased over time by including voice in online gaming (Jenson \& de Castell, 2011).

How can women effectively lead in communities that are hostile toward them, with so many preexisting biases and schemata that are difficult to tear down? Eagly and Carli (2003) say that "effectiveness of the leader behaviors depends on contextual variables, such as the nature of the task and the characteristics of the followers" (p. 808). While mostly viewed in an organizational context, their findings can provide implications and guidelines for women trying to lead in online gaming communities, both within gameplay videos themselves and other games media, like blogs or gaming journalism (Armstrong \& McAdams, 2009; Chess \& Shaw, 2015). It is also worth noting that women are often held to higher standards than men are, and this is especially true in communities that are not as welcoming to women (Eagly \& Carli, 2003). Among the same trends that previous research uncovered, Eagly and Carli (2003) found that female leaders were evaluated more harshly than male leaders when evaluated by men, and female leaders were more positively evaluated by other women. This is to say that in terms of leadership, the identity of the speaker and the receiver are important in evaluating the speaker's leadership abilities.

Performance, trustworthiness, and leadership ability are constructs that are evaluated differently than confidence and credibility. Confidence and credibility seem to be evaluated in terms of the matchup hypothesis, in that video gaming is considered a predominantly masculine pursuit. Because gaming is considered a masculine activity, 
men are more likely to be evaluated as more confident and credible in discussing gaming because men and gaming line up with preconceived notions of the pastime as a whole. As the research discussed illuminated, performance, trustworthiness, and leadership seem to operate differently. Because individuals perceive those like them to be better leaders, more trustworthy, and have overall better performance - the gender identity of those on the receiving end of a message is likely to interact with perceptions of the source of information in a video gaming context. This is to say that evaluations of these three constructs are likely to be higher if an individual's gender identity lines up with the gender identity of an information source.

Such evaluations allude to the notion that there are many factors interacting that influence how women are perceived in gaming communities. Gender identity of the perceiver seems to have effects on many levels, and perceptions of women as a gender identity in online gaming have had a contentious go. The gender identity of a perceiver can have impacts on how they see others with different gender identities in terms of performance, how much they trust the speaker, as well as how well they believe the speaker can take on leadership roles. Thus, gender of the receiver of information and previously existing schemata that the perceivers hold both interact to formulate perceptions of incoming information. Thus, I propose the following hypotheses:

H3: Gender identity will moderate the evaluation of the performance of a player in a narrated gameplay video in such a way that participants will evaluate the voice-over narrator that aligns with their gender identity more positively than a voice-over that does not.

H4: Gender identity will moderate the evaluation of trustworthiness of a voiceover narrator in such a way that participants will evaluate the voice-over narrator 
that aligns with their gender identity as more trustworthy than a voice-over that does not.

H5: Gender identity will moderate the evaluation of the leadership ability of a voice-over narrator in a gameplay video in such a way that participants will evaluate the voice-over narrator that aligns with their gender identity as having greater leadership ability than a voice-over that does not.

In other words, participants will evaluate the performance, trustworthiness, and leadership ability of the speaker that aligns with their own gender identity more positively than the speaker that does not align with their gender identity. So, respondents with a feminine gender identity will evaluate the performance, trustworthiness, and leadership ability more favorably for the female speaker than they will for the male speaker. Alternatively, those with a masculine gender identity will evaluate the same constructs more positively for a male speaker than they will for a female speaker. Both the gender identity of the participant and the gendered qualities of either speaker (either male or female) matter in evaluating the aforementioned constructs. In terms of credibility and confidence, only the perceived gender of the speaker matters in such evaluations regarding topics that have an already existing gendered nature (as in video games and their association with masculinity). Because the voice of a speaker that aligns with the gendered nature of a topic will be seen as having higher aptitude discussing such matters, evaluations of their credibility and confidence in discussing those matters will be evaluated more positively.

As established, gender stereotypes and existing conceptions of what maleness and femaleness mean inform individual's perceptions about others, and people often rely on said perceptions when receiving information. Schema theory also helps build an 
understanding of how information is processed based on previously existing constructs and schemata that people hold (Bem, 1981). Other schemata also influence perceptions and information processing, particularly in terms of gender and heuristic preconceptions about individuals based on gendered attributes (Bem, 1981; Knobloch-Westerwick \& Hoplamazian, 2012; Linek et al., 2010).

Many aspects of the contentious environment in gaming culture that female participants in the culture endure paint a picture of the environment that women must navigate in the medium, ranging from how women are portrayed in gaming to how they are treated in gaming-related communities, as per the \#GamerGate controversy to interactions with in-game characters like Ji Firepaw in WoW (Braithwaite, 2013; Chess \& Shaw, 2015). Further, technologies themselves become gendered, as in Royse and colleagues' (2007) examination of technologies of the gendered self-gaming has been shown to be one such gendered technology. Such gendering leads people to process information in ways that match gender to certain concepts (such as gaming), which the matchup hypothesis tries to better explain (Linek et al., 2010). As gender and societal norms and assumptions relating to gender stereotypes impact how people receive and process information — both in terms of the perceiver's gender and the information being received - certain cues (in the current study, voice specifically) awaken such processing and can thus influence how an individual interprets incoming information (Bem, 1981; Eagly \& Carli, 2003; Lynch \& Schuler, 1994). 


\section{Chapter 3: Methods}

\section{Participants}

Using Amazon Mechanical Turk, an advertisement was placed online to recruit participants for this study. The recruitment message solicited any gamers 18 and older residing in the United States of America with a positive Mechanical Turk rating, meaning that their reputation on the service was acceptable. After agreeing to an informed consent form which outlined the minimal risks associated with participation in the study, as well as the mandatory inclusion criterion of having the ability to watch a gameplay video and hear its audio (see Appendix B), participants were able to proceed with completing the survey. Risks associated with participation were minimal, as respondents may have felt slight discomfort with watching a segment of violent video game content and responding to personal questions about individual gender identity.

On Qualtrics, 398 participants started the survey, and all completed the informed consent. 322 watched the complete video, thus 76 participants (19.1\%) were omitted from analysis, as they did not receive the experimental stimulus. Because the final analysis depended on a masculine and feminine gender identity dichotomy, 14 (3.5\%) individuals who had a neutral gender identity as per the gender identity scale used in this study were excluded from analysis. Similarly, 3 participants $(0.75 \%)$ indicated 'other' when asked with which gender they most closely identified and were excluded from the final analysis due to the dichotomous nature of the current study. This study sought to examine only those who actively play video games, and 5 participants (1.3\%) indicated that they did not participate in the medium and were also excluded. As to not throw off 
the final analysis, 7 individuals were omitted from the sample for not answering a sufficient number of questions after receiving the experimental stimulus, resulting in $1.76 \%$ of participants being dropped from the final analysis. Finally, a manipulation check toward the end of the survey was included before demographic information assessments and asked the participant to indicate what they perceived the gender of the speaker in the gameplay video to be, and 19 participants (4.8\%) responded incorrectly. Only those who correctly responded to the manipulation check and passed all other exclusionary criteria were included in the final sample $(N=274)$.

The average age of the final sample was $33.5(S D=10.03, M d n=31)$ and ranged from 20 to 70 . Participants spent an average of $14.4(S D=12.67)$ hours per week playing video games. $66.1 \%(n=181)$ of participants said that they use technologies like Twitch, YouTube Gaming, and online tutorials, and a smaller percentage $(n=93,33.9 \%)$ of respondents said that they did not. Those who use such technologies spend an average of $2.87(S D=3.52)$ hours per day using them. Respondents were also asked if they had played the game featured in the experimental stimulus (Fallout 4$)$, and $40.5 \%$ had $(n=$ $111)$, and $59.5 \%(n=163)$ had not.

\section{Procedures}

This experiment employed a two-by-two (sex of the voice-over narrator, reported gender identity of the participant) between-subjects design. After the respondent agreed to the informed consent at the beginning of the survey, they were able to watch a narrated tutorial video featuring gameplay from Bethesda Game Studios’ 2015 role-playing game release, Fallout 4. Fallout 4 was an appropriate choice of video game to include for a 
few reasons. First, like many other RPGs, it offers a vast variety of in-game activities. Exploration, combat, achievement, and creative capabilities interact to form a game that has something to offer a broad array of demographics. It is also a single-player game, thus eliminating the competition element often present in many FPS games and increases appeal to varying types of players, as previous research indicates that men tend to gravitate toward competitive or achievement elements in games, while women seek more social or creative play motivations (Shen, Ratan, Cai, \& Leavitt, 2016). Fallout 4 truly affords opportunities for many different types of gamers with a variety of different playstyles, thus making it a good option to include in the current study.

Two tutorial videos were created for this study, a male voice-over or a female voice-over to narrate the featured gameplay. The gameplay for both videos was exactly the same; one video was recorded with only gameplay and no featured narration, and a script was written after the gameplay video was recorded. Audio was recorded later and layered over the already existing gameplay. The male and the female narrators followed the same dialogue scripting (Appendix B). To account for consistency in pacing, time stamps were added into the body of the script. The script described 1) where the gameplay was taking place and the goals of the situation depicted in the video, 2) the resolution of the gameplay action, and 3) the next steps to be followed after the video ended to achieve the in-game goals. Additionally, if the recording did not match the timing of the video, it was re-recorded and re-edited so the pacing for both the male and the female-narrated videos matched in terms of timing. There were capitalized portions marking where emphasis should be placed, however no markers for tone, pitch, or other 
intricate linguistic mechanisms were included. This decision was made to ensure external validity with an all-gamer sample. As this population is more familiar with the nature of video game tutorials, having narration sound too scripted would not elicit meaningful results. It is also important to mention that the narration featured in the experimental stimuli was not robotic sounding akin to iPhone's Siri or Microsoft's Cortana. The narration was human-sounding, providing as close to an actual video game tutorial that one would see online as was possible to accomplish with the resources available.

Randomization was employed within the survey programmed in Qualtrics to ensure equal chance of exposure to the two experimental conditions (see Appendix C). After viewing the video, the respondent was asked to evaluate the player's performance, confidence, credibility, trustworthiness, and leadership ability, and a group of questions toward the end of the survey assessed general demographic information. Additionally, a manipulation check was included to ensure the video was watched with the accompanying audio, which asked the respondent to confirm their perceived gender of the speaker, which was either male or female. The survey instrument also contained a timer during the video portion to ensure that the respondent viewed the gameplay tutorial video in its entirety.

\section{Measures}

Gender identity. The gender identity of the participants is conceptualized as how closely they identify with masculine or feminine traits, regardless of biological sex. While biological sex (male, female, or other) was included in the questionnaire to serve 
as a demographic backdrop, gender identity was the primary factor from which the hypothesized differences would stem. To assess the gender identity of participants, the sexual identity scale (SIS) developed by Stern, Barak, and Gould (1987) was used. The scale is a four-item Likert-type measure that asks respondents to evaluate their perceived gender identity, with anchors at $1=$ very masculine and $5=$ very feminine. Sample items included "I feel as though I am..." and "I look as though I am..." to which respondents indicated very masculine, very feminine, or somewhere in between. Final reliability for this measure was $\alpha=.91$, which is good reliability. For analysis, the scale was collapsed into one measure and those scoring less than 2.5 on the scale were considered masculine, and those scoring higher than 2.5 were considered feminine. For the purposes of analysis, anyone who had a neutral score (2.5) was omitted from analysis, as there were no hypothesized differences that would stem from androgyny.

Player performance. Overall player performance was conceptualized as how well the player featured in the video achieved goals within the game environment. Performance was operationalized as a 5-point Likert-type scale modified from the new general self-efficacy scale (Chen, Gully, \& Eden, 2001). The scale was modified from the original version in two ways. First, as the original scale was developed to measure self-efficacy, the scale needed to be adapted to evaluate someone else's level of adeptness in a given situation. Second, the scale needed to be adapted to fit the context of video game play. For example, an original scale item read as "I will be able to achieve most of the goals that I have set for myself" (Chen et al., 2001, p. 79). The modified version reads as "The player was able to achieve the goals they set out to accomplish." The scale 
is anchored at $1=$ strongly disagree and $5=$ strongly agree. Final reliability for this scale in the current study was $\alpha=.89$, which is good reliability. For analysis, all eight items were collapsed into a single variable and aggregated into one score.

Confidence. Adapted from a series of scales measuring several dimensions of consumer confidence in marketing messages, the measure of confidence evaluates the player in the video's comfort levels in relaying information to the video viewers, or perceived assurance of the narrator's own abilities (Bearden, Hardesty, \& Rose, 2001). The original scale measured six dimensions of consumer confidence including information acquisition, consideration-set formation, personal outcomes decision making, social outcomes decision making, persuasion knowledge, and marketplace interfaces. For this study, three dimensions of confidence (information acquisition, personal outcomes, and social outcomes) were used and adapted to fit the context of video games and the viewer's perception of the player in the video's confidence. For example, an original scale item for information acquisition was "I know where to find the information I need prior to making a purchase" and was modified to "I could ask the speaker in the video for more information about the game" (Bearden et al., 2001, p. 125). In total, this Likert-type scale contains 15 items with anchors at $1=$ strongly disagree and $5=$ strongly agree. All items under personal outcomes were reverse coded, and final scores for all scale items were aggregated into a single score for analysis. In the current study, the combined 3-dimension scale achieved good total reliability where $\alpha=.88$.

Credibility. Credibility of the speaker is conceptualized as how knowledgeable the viewer perceives the speaker to be on the subject matter of gaming. A two-dimension 
Likert-type scale developed by Kang (2010) to measure blog credibility was used. First, the credibility of the speaker was assessed. This subset of the scale contained five items - knowledgeable, influential, passionate, transparent, and reliable. The scale was formatted as a list of these traits, with a one-sentence prompt asking the respondent the level to which they thought the speaker held any of the aforementioned qualities. The second dimension of this scale assessed the overall credibility of the relayed information. Similarly, it was formatted in such a way as to ask the respondent if they felt the information was authentic, insightful, informative, and consistent, among five other items. In total, the two scales contained 14 items. Scale items were anchored at $1=$ strongly disagree and 5 = strongly agree. The two dimensions were aggregated into a single value for analysis, and the scale had good reliability $(\alpha=.93)$.

Trustworthiness. Ohanion (1990) developed a series of semantic differential scales to assess perceived speaker trustworthiness, attractiveness, and expertise in terms of speakers in advertisements featuring celebrity endorsers. Trustworthiness for the purposes of the current study is defined as the level of acceptance a listener has for a speaker's message based on the perceived credibility of the speaker in question. The five-item semantic differential scale includes items 1) dependability, 2) honesty, 3) reliability, 4) sincerity, and 5) trustworthiness, among their inverses with five points that participants could select between the two extremes. For the current study, reliability was reported at $\alpha=.92$, which is good reliability. Results were aggregated into a single item, and high scores indicate high levels of trustworthiness, low scores indicate low levels of perceived trustworthiness. 
Leadership ability. Finally, a scale for leadership ability was adapted from Phillips and Lord (1982) for the current study to relate to gaming tutorials. The working conceptualization of leadership for the current study is effectiveness in task management and depicting appropriate examples in-game that viewers of tutorials can learn from and base their own gameplay on, stemming from the examples illustrated by the speaker in the video. Operationally, leadership is defined as a 10-item Likert-type scale with anchors at $1=$ strongly disagree and $5=$ strongly agree, and including scale items like 'the player was willing to admit when they made a mistake' and 'the player maintained manageable performance standards.' Initially, the scale elicited a poor reliability score ( $\alpha$ $=.53$ ). One item was omitted from final analysis that read 'the player did things without explaining their actions.' After the omission, the scale had acceptable reliability, which was reported as $\alpha=.75$. For final analysis, the scale was collapsed into one item so a single score was used.

Demographics. In addition to the series of scales described above, demographic items including age, gender identification, and whether or not the participant identified as a gamer were included in order to garner a clearer picture of the respondents of this study. Another measure assessing which types of games the respondent played was also included in an effort to see if any trends emerged as far as their assessments of other players and experience with varying types of games had any implications on the results. This scale listed a series of genres including role-playing games, first-person shooters, creative games, among others. The respondent could indicate that they $1=$ never play that genre, or that they $5=$ always play that genre. This scale was dichotomized for final 
analysis, to simply paint a picture of the sorts of games that the sample was overall interested in. Also, a question was included to see if the respondents had previous experience with the game featured in the stimulus video (Fallout 4) to see if that had any impact on the results.

\section{Analysis}

To ensure conclusive results, data were not included if the participant failed the manipulation check, or if did not respond to all scale items after the experimental stimulus. Additional criteria were required to be included in final analysis, which was detailed above. For non-interaction hypotheses (H1 and H2), single-factor analysis of variance (ANOVA) tests were used to analyze the data. In interaction hypotheses (H3, H4, and H5), participants' gender identity and the experimentally manipulated narrator sex were tested against the dependent variables by way of a series of multiple-factor analysis of variance (ANOVA) tests. 


\section{Chapter 4: Results}

The participants in this study had a fairly even split in terms of gender identity. Per the gender identity scale used, $52.2 \%$ of participants were masculine-identifying $(n=$ $141)$ and $47.8 \%$ of participants were feminine-identifying $(n=129)$. Those participants who did not fit into a masculine/feminine, male/female binary were excluded from final analysis, as the hypotheses did not account for those with neutral or other gender identities. Interestingly, when asked to identify their own gender identity, $65 \%$ of respondents indicated that they identified as male $(n=178)$, while $35 \%$ of participants indicated a female identity $(n=96)$. A chi-square analysis was conducted to see if there was any significance regarding which gender that men and women identified with. The results were significant, $\chi^{2}(1, N=270)=162.82, p<.001 .100 \%$ of participants who identified as masculine were male $(n=141)$ while $0 \%$ of female participants were masculine-identifying $(n=0)$. Interestingly, $25.6 \%$ of male participants were feminineidentifying $(n=33)$, and $74.4 \%$ of female participants were feminine-identifying $(n=$ 96).

Additionally, respondents were asked a series of questions about which types of games they played. Assessments of game types were presented on a scale in which participants could indicate how frequently they played certain genres $(1=$ never, $5=$ always). This scale was dichotomized for final analysis, and participants who indicated rarely, sometimes, often, or always to a certain genre were considered to play it, and those who indicated never were considered not to play that particular genre. The breakdown of game genres played by participants is as follows: First-person shooters, $90.5 \%$ yes $(n=248), 9.5 \%$ no $(n=26)$; role-playing games, $92 \%$ yes $(n=252), 8 \%$ no $(n$ 
$=22)$; third-person adventure, $88.3 \%$ yes $(n=242), 11.7 \%$ no $(n=32)$; survival horror, $80.3 \%$ yes $(n=220), 19.7 \%$ no $(n=54)$; creative, $78.1 \%$ yes $(n=214), 21.5 \%$ no $(n=$ 59); MMORPG, $66.4 \%$ yes $(n=182), 33.2 \%$ no $(n=91)$; platformers, $80.3 \%$ yes $(n=$ $220), 19.3 \%$ no $(n=53)$; racing, $68.2 \%$ yes $(n=187), 31.4 \%$ no $(n=86)$; sports, $54 \%$ yes $(n=148), 45.3 \%$ no $(n=124)$; and other, $51.8 \%$ yes $(n=142), 45.3 \%$ no $(n=115)$. 'Other' games indicated by the participants included tablet/mobile games, strategy and turn-based strategy games, card games, puzzle games, simulation games, fighting games, tower defense games, x-rated games, roguelike games, rhythm/music games, multiplayer online battle arena (MOBA) games, and visual novels.

The majority of participants also identified as gamers, with $86.1 \%$ of participants claiming the gamer identity $(n=236)$ and $13.9 \%$ of participants rejecting that identity $(n$ $=38$ ). Whether or not the participants identified as gamers was not a factor in exclusion from final analysis, though actually playing video games was. In terms of the experimental conditions for the current study, randomization within Qualtrics allowed for a fairly even split as for who received the male-voiced stimulus $(n=141,51.5 \%)$ and those who received the female-voiced stimulus $(n=133,48.5 \%)$.

H1 predicted that a male narrator in a voiced gameplay video would be evaluated by respondents as more confident overall than a female narrator would be. A one-way ANOVA was conducted to evaluate what effect the voice of a narrator would have on evaluations of confidence in a tutorial speaker. The hypothesis was not supported, $F(1$, $272)=2.30, p=.13$, partial $\eta^{2}=.008$. Contrary to the prediction made by $\mathrm{H} 1$, the evaluation of confidence by participants for the female speaker was slightly higher $(M=$ 
$3.89, S D=0.54)$ than confidence evaluations of the male speaker $(M=3.79, S D=0.61)$.

While evaluations for the female speaker were slightly higher, the difference in confidence evaluations was not statistically significant.

Similarly, H2 predicted that a male narrator in a gameplay tutorial would be evaluated as being more credible to discuss gaming than a female narrator would be. Again, a one-way ANOVA was conducted to evaluate the effect of narrator voice in terms of gender on credibility evaluations of the speaker by participants. H2 was not supported as the evaluations for the female speaker were slightly higher than evaluations of the male speaker, though the difference was not statistically significant, $F(1,272)=$ $0.84, p=.36$, partial $\eta^{2}=.003$. Once again, contrary to the prediction made by $\mathrm{H} 2$, credibility evaluations of the female speaker were slightly higher $(M=3.97, S D=0.55)$ than credibility evaluations of the male speaker $(M=3.90, S D=0.64)$. Both $\mathrm{H} 1$ and $\mathrm{H} 2$ were also run as multiple-factor ANOVAs with the added caveat of participant gender identity per the gender identity scale, and no significant patterns emerged and gender identity did not have a moderating effect on evaluations of narrator confidence and credibility.

H3 predicted that respondent gender identity would have a moderating effect on evaluations of player performance based on the gender of the voice of the video narrator, which was either male or female. There was no effect of the stimulus on evaluations of player performance; thus the experimental stimulus did not elicit the hypothesized result, $F(1,266)=0.95, p=.33$, partial $\eta^{2}=0.004$. Contrary to the prediction made, the performance of the female narrator was evaluated similarly overall by both masculine- 
identifying participants $(M=4.2, S D=0.5)$ and feminine-identifying participants $(M=$ 4.2 $S D=0.6$ ). The male narrator's performance was evaluated more negatively overall by both masculine-identifying participants $(M=4.1, S D=.6)$ and feminine-identifying participants $(M=4.2, S D=.6)$. Thus, $\mathrm{H} 3$ was not supported. The interaction effect which was the stimulus and its interaction with individual gender identity proved not significant, showing that gender identity of the participants and the gender of tutorial narrator did not produce a significant interaction, $F(1,266)=0.06, p=.809$, partial $\eta^{2}=$ 0.0. The gender identity of the participant additionally did not produce a significant effect on evaluations of player performance, $F(1,266)=0.45, p=.50$, partial $\eta^{2}=0.002$. Thus, none of the hypothesized effects or interactions proved to be statistically significant.

The prediction made by $\mathrm{H} 4$ was that a respondent's gender identity would moderate evaluations of trustworthiness for the speaker in the narrated gameplay video. Though the evaluations were in the predicted direction, in that participants evaluated the trustworthiness of the narrator that aligned with their own gender identity more favorably, the overall results of trustworthiness of the speaker in the tutorial bore no statistical significance. Participants did not evaluate the speaker that aligned with their gender identity as more trustworthy than the speaker that did not, as masculineidentifying participants evaluated the male speaker $(M=4.34, S D=0.78)$ as equally trustworthy as feminine-identifying participants receiving the same stimulus $(M=4.31$, $S D=0.71)$ did. Masculine-identifying participants evaluated the female voice-over as about as trustworthy $(M=4.37, S D=0.63)$ as feminine-identifying participants receiving 
the same stimulus $(M=4.42, S D=0.65)$ did. These evaluations were essentially same, thus marking the reason for no statistical significance. The interaction effect of gender identity and the stimulus on evaluations of narrator trustworthiness was $F(1,266)=0.26$, $p=.610$, partial $\eta^{2}=0.001$, which was not a significant effect. The main effect of the stimulus was $F(1,266)=0.78, p=.377$, partial $\eta^{2}=0.003$, and the main effect of gender identity was $F(1,266)=0.01, p=.926$, partial $\eta^{2}=0.0$. Thus, H4 was not supported.

Gender identity was predicted to influence evaluations of leadership ability based on the gender of the speaker in the video. Significant results were not produced. Masculine-identifying participants evaluated the male speaker as having slightly greater leadership ability $(M=3.88, S D=0.53)$ than feminine-identifying participants $(M=3.82$, $S D=0.60$ ), and for the female speaker, feminine-identifying participants evaluated the speaker as having the same leadership ability $(M=3.91, S D=0.54)$ as masculineidentifying participants $(M=3.89, S D=0.44)$ did. Neither the main effects nor the interaction effect produced significant results. The interaction effect of gender identity and the stimulus on leadership ability evaluations was $F(1,266)=0.40, p=.526$, partial $\eta^{2}=0.002$. The effect of the stimulus (male or female video narrator) was $F(1,272)=$ $0.58, p=.449$, partial $\eta^{2}=0.002$. The effect of participant gender identity on leadership ability evaluations was also not significant, $F(1,272)=0.06, p=.804$, partial $\eta^{2}=0.0$. Thus, H5 was not supported. As the scale for leadership ability was an adapted scale from previous research, the original version with no excluded items was used in the same statistical test, and no different patterns of significance emerged with the original scale with all items included. 


\section{Chapter 5: Discussion}

In some cases, no significant findings can be just as interesting as statistically significant findings. $\mathrm{H} 1$ predicted that a male narrator overall would be evaluated as more credible to discuss gaming than a female narrator would be, and this hypothesis was not supported. Similarly, $\mathrm{H} 2$ proposed that a male narrator would be considered more credible to discuss gaming than a female narrator would be and no significant results were produced. Hypotheses three, four, and five asked respondents to evaluate the performance, trustworthiness, and leadership ability of the narrators in the experimental stimuli, and no significant differences were found between evaluations of the male narrator and evaluations of the female narrator.

In the current study, no statistically significant findings regarding the proposed hypotheses is indicative of a potentially changing tide. Part of this changing landscape could be a result of the integration of new technologies to gaming, increasing visibility of more and varied participants in the medium—not solely the stereotyped male gamer demographic. Additionally, the genre of video game tutorials does differ slightly from that of Twitch and YouTube Gaming. Potentially, because the nature of video game tutorials is to help players navigate through in-game tasks, evaluations overall were more favorable for each narrator. Game tutorials are generally positive and not approached by the narrator with competition in mind, but their sole purpose is to assist players who may be having a difficult time accomplishing in-game goals. Twitch and YouTube Gaming are more centered on broadcasting live gameplay, and thus competitive elements may more readily surface. While some Twitch streams are used to help individuals navigate 
through in-game tasks, this is not the sole purpose of the genre as it is in online video game tutorials.

This section will highlight the potential changes in video gaming that these results allude to in regards to gender and technology. Implications for schema theory and social agency theory will be highlighted. Limitations will be discussed, as well as potential areas for future research to explore in terms of the varying communication technologies that have recently been introduced to video gaming, and discovering what these communicative changes mean for participants in the medium.

\section{Implications for Gender and Gaming}

As previously stated, according to the most recent data available regarding participation in gaming, men and women play video games at almost equal rates, but the medium is still considered a male pursuit despite the makeup of participants (Lofgren, 2015). As evaluations of a male narrator and a female narrator featured in the current study were similar, perhaps the integration of new communication technologies in gaming are creating an environment in which women are more visible and are thus more commonly seen as active and apt participants in the medium. While $90 \%$ of the top-rated Twitch live streamers are male, the top female streamers have large audiences and are thus effectively increasing the visibility of female gamers (Withers, 2015). Further, previous research showed individual gender identity to be a factor in the processing of incoming information, in this case-video game tutorial narration. Individual identity did not seem to be a factor in the evaluations made by participants, so more work should be done to see in which contexts this is a factor in evaluating incoming information. This 
could also be attributed to the differences in genre from video games, to game tutorials, to live streams featured on Twitch and YouTube gaming. Because such videos are meant to be helpful, it could likely be a reason that the respondents did not evaluate the player as harshly.

Corroborating the findings of the current study, Shen and associates (2016) conducted an analysis using longitudinal server data from two MMO games, EverQuest II and Chevaliers' Romance III. Their study is one of the first to explore performance by gender in MMO games based on longitudinal data gathered directly from the featured games' servers. Using two different metrics for performance (speed of advancement ingame based on time played and time between leveling up to each level ), the researchers found that women performed at the very least as well as men did, and in some cases even better (Shen et al., 2016). These findings indicate that a significant difference in performance in these types of games does not exist, contrary to perceptions held that women are not as skilled as men are in this domain. The only gendered differences that emerged in this study were that women tended to play less or quit the game earlier than men did (Shen et al., 2016). While men and women have been previously shown to have different motivations for playing video games (e.g., men for achievement-oriented reasons and women for socially-motivated reasons), these play motivations seem to have no bearing on performances in the medium itself. The perception that women do not play as well as men is revealed false by this study, but the stereotype is continuously perpetuated and reinforced, discouraging women from engaging with the medium, which 
further contributes to disparities in STEM and computing-related fields (Shen et al., 2016).

Shen and colleagues (2016) also suggest that as women play less or quit earlier than men do in MMO games (at least per the data in their study), the stereotype continues to exist. To contextualize this, the authors used stereotype threat theory. The theory posits that the salience of negative stereotypes associated with one's demographic characteristics push individuals to conform to those stereotypes (Shen et al., 2016). Hopefully though, the fact that women are increasing their visibility in video games communities and content will help in shifting the stereotypes associated with their participation or lack thereof, lessening the perception of a divide and contributing to fewer women subscribing to stereotypes regarding the medium.

In addition to this increased visibility, female streamers have more control than ever before as to what does or does not happen on their Twitch channels. Women still do deal with a fair amount of negativity in the comment feeds and interactions through Twitch, but they can, in a way, control to what extent the negativity remains visible (Withers, 2015). In forums and other online gaming outlets, such control is not held by the participant which allows for greater visibility of negative comments and interactions previously seen in $W o W$ forums and other outlets, and in the 'dickwolves' incident (Braithwaite, 2013; Salter \& Blodgett, 2012). More visibility of women and greater control over hostile interactions could effectively be working together to create an environment in which women are met with less visible hostility and greater online presence overall. These phenomena could work together to lessen negative feelings 
toward women in the gaming arena. Perhaps one factor that reinforces the notion that women are not 'welcome' in gaming environments is the notion that a loud minority is skewing perceptions of the medium as a whole. As the results in the current study indicate, men and women are viewed at least in the context of video game tutorials quite similarly. The perception that women are unwelcome could be perpetuated by a small portion of the gaming community vocalizing such criticisms and harassment of female gamers, lending credence to perceptions of women as less skilled or unwelcome players. Future research should attempt to tap into these attitudes and build on the current study, and seek to provide an assessment of real attitudes toward female gamers in a variety of related communities.

Another possible explanation is that these no-findings can be linked to an increase of awareness of what female gamers have had to deal with in an effort to navigate their online identities. In light of recent controversies like what has been seen during the height of \#GamerGate, more people are perhaps aware of the contentious environments that women often face, and they bring that awareness into the gaming domain as identity as a gamer and offline identities intersect in the virtual experience (Royse et al., 2007; Williams et al., 2009). Additionally, this visibility could be leading to the overall gendering of video games as shifting, not necessarily in content, but in acknowledging overall the greater presence of female gamers (Royse et al., 2007).

\section{Schema Theory and Social Agency Theory}

It is unclear whether or not the respondents had previous referents in place that would cause them to evaluate women more poorly than men (Bem, 1981; Tversky \& 
Kahneman, 1974). Perhaps this is something best assessed with a more qualitative lens, as interviews and focus groups could be a better way to evaluate individuals' previous experiences with the medium and interactions with others in it. With that said, it is possible that video gaming could be undergoing a code shift of sorts, especially considering the recent media coverage of gaming-related controversies, and the growing popularity of female live streamers via Twitch and YouTube Gaming, changing the way participants are evaluated (Chess \& Shaw, 2015; Dockterman, 2014). This phenomenon also calls out to social agency theory (SAT), which suggests that individuals apply norms gained from social interaction to media which can, in turn, influence learning outcomes (Linek et al., 2010). Voices and pictures act as social cues per SAT, and with the social cues surrounding gaming, interactions therein may also be shifting (Linek et al., 2010). Potentially, though, as this study featured voice narration free of gendered speech patterns, the stripping away of gendered content lent itself to more egalitarian evaluations of both video narrators featured as stimuli in the current study. It could be that because speech patterns typically associated with masculine and feminine speech were not embedded in the stimuli that these differences in perspective did not emerge. More research should seek to include gendered speech patterns in a similar design in an effort to evaluate whether or not such speech patterns delivering the same content would make a difference in how the narrator is perceived. Further, perhaps narrator appearances being visible via picture-in-picture capabilities would elicit more differences in evaluations. As Sellnow and Trienen (2004) found, the appearance of a speaker did matter in terms of how people were evaluated in an academic setting. Perhaps these same 
differences would be more readily apparent if the current study was conducted with the video game tutorial narrator visible to the respondent.

Changes in the very content of games, too, could be a factor in more equal evaluations of women in games. The prevalence of more games with strong female protagonists and supporting characters, like recent iterations of the Tomb Raider franchise and The Witcher 3: Wild Hunt which features strong female characters that are integral to the storyline and its resolution, rather than just there for viewing pleasure or in need of being rescued, could be changing the ways in which women are viewed in the medium. These content changes could be increasing the presence of women in games content, and thus changing the schemata and referents that people draw on when making evaluations of other players, or processing incoming information about gaming more generally (Bem, 1981; Tversky \& Kahneman, 1974). Game content has historically perpetuated the idea of hegemonic masculinity, but the recent changes in strong female leads becoming more prevalent, alongside greater visibility of women via live streaming, could be contributing to less hostile behaviors on behalf of the user base as a result (Pulos, 2013; Schippers, 2007).

\section{Technology}

The lack of statistically significant findings regarding the current study's hypotheses seem to beg the question of whether or not technology as a whole is becoming a less gendered enterprise. As Royse and colleagues (2007) discussed, technologies as a whole do become gendered through mediated means that attach a gender to a technology, as was seen in the past with the telephone and in modern times, 
gaming. As gaming is becoming more and more communicative, equal participation by men and women is seemingly more acknowledged because women's participation is more heuristically available (Pulos, 2013; Schippers, 2007; Tversky \& Kahneman, 1974). The availability of wider spread participation by diverse demographics could explain why concepts like confidence, credibility, performance, trustworthiness, and leadership ability are more equally attributed to both men and women in the context of narrated gameplay tutorials. Technology evolves quickly, and with this evolution it could be said that the user bases are evolving alongside.

\section{Limitations and Directions for Future Study}

This study was limited in some ways. First, schema theory which was used as a lens for this study, was developed at a time before much academic theorizing about gender had been introduced into the field of knowledge. Future research should examine schema theory deeper in terms of communication technologies and build on the perspectives offered by it to better explain modern phenomena, while additionally lending itself to contemporary notions of gender identification (Bem, 1981). Further, as the use of the SIS and self-identified gender elicited significant results, more research in the future should try to move past the gender binary that much research has become accustomed to. Using scales like the SIS in conjunction with self-identified gender may illuminate findings that are different from what has been revealed in the past, so a call to examine gender in terms of both self-identified attributes and scales measuring masculinity and femininity would benefit many fields of research, and especially in this case - studies about gender and its role in video game environments. Such studies may 
even further advance the considerations offered by schema theory; while the theory still offers valuable perspectives through which to look at communication phenomena today, more data regarding its implications on technology and varying gender identities would benefit the field of communication as a whole.

Second, there were a few problems with the overall sample for this study. While 398 people started this survey, only 274 were used for final analysis. Many were dropped for not meeting the required criteria (as mentioned previously), but many also dropped out of the experiment before the stimulus or immediately after completing the informed consent. No emergent patterns regarding which stimulus participants dropped out after exposure occurred, as most participants who dropped out did so before the stimulus was introduced. As this data was collected via Amazon Mechanical Turk, the best measures for collecting good responses were enacted, though it was difficult to control outside of the criteria set via the website. Potentially, collecting data for an experiment like this in the future may benefit from a lab setting in which the researchers can ensure the study requirements are being met.

Sampling strategies to accomplish an all-gamer sample may also need further development, as previous research examining games communities often accessed data from video game servers themselves (Shen et al., 2016; Williams et al., 2009). While this is an effective way to ensure an all-gamer sample in studies such as these, there is no variability in terms of what kinds of games such respondents are playing as the sample would be drawn from one game and one game only. Perhaps accessing populations via several different games would elicit different results, and more research in this domain 
should seek to attain as diverse a sample as possible while still maintaining an all-gamer focus. Additionally, the sample for this study included only those who actively participate in gaming. Future research may want to consider examining both gamers and non-gamers in an effort to better understand how those unfamiliar with the medium perceive others in the context of gameplay.

The experimental stimuli featured only vocal cues for the participants to evaluate. While some online tutorials feature solely vocal cues, many also employ the use of picture-in-picture videos of the speaker alongside the gameplay featured in the video. Further, Twitch and YouTube gaming have this feature as an option and many live streamers employ it while broadcasting their gameplay. Future research should seek to include both vocal and video cues for participants to evaluate alongside gameplay, as previous research has also relied on voice and visual cues, and presenting a stimulus like this to a gamer audience would greater ensure external validity (Linek et al., 2010).

\section{Conclusion}

While the world of video gaming is nowhere near perfect, these results can be interpreted as indicative of a potentially changing arena. Women and men in this study were not perceived differently in what is considered a male-dominated domain. These trends in how women are perceived as participants of the medium are a good sign for women wishing to enter STEM careers, as perhaps more positive and equal views of women in gaming can push younger girls to have an interest in these careers because the harassment and negative interactions could be progressively lessening. These results indicate that there is a possibility for less hostility and negativity toward female gamers in 
terms of how confident and credible they are to relay information about gaming, and how their performances, trustworthiness, and leadership ability can be met positively rather than as an intrusion.

These trends could translate to technology careers, and participants in gaming can form a unified front to challenge the perceived norms of the medium that exist. Research in the future could benefit the field of video games as a whole by examining some of these same questions with both audio and visual cues, perhaps presented in the format of the Twitch user interface. Do visual cues make a difference when combined with vocal cues, and does the genre being broadcasted make a difference as to how these players are perceived? While the results of this study suggest that the situation does seem to be getting better, more research in this area can develop a better environment for inclusiveness and equal opportunity in gaming-related environments and careers in technology. 


\section{References}

Armstrong, C., \& McAdams, M.J. (2009). Blogs of information: How gender cues and individual motivations influence perceptions of credibility. Journal of ComputerMediated Communication, 14, 435-456. doi: 10.1111/j.1083-6101.2009.01448.x

Bearden, W.O., Hardesty, D.M., \& Rose, R.L. (2001). Consumer self-confidence: Refinements in conceptualization and measurement. Journal of Consumer Research, 28(1), 121-134.

Beck, V.S., Boys, S., Rose, C., \& Beck, E. (2012). Violence against women in video games: A prequel or sequel to rape myth acceptance. Journal of Interpersonal Violence, 27(15), 1-16. doi: 10.1077/0886260512441078

Bem, S.L. (1981). Gender schema theory: A cognitive account of sex typing. Psychological Review, 88(4), 354-364.

Braithwaite, A. (2013). 'Seriously, get out': Feminists on the forums and the War(craft) on women. new media \& society, 16(5), 703-718. doi: $10.1177 / 1461444813489503$

Chen, G., Gully, S.M., \& Eden, D. (2001). Validation of a new general self-efficacy scale. Organizational Research Methods, 4(1), 62-83. doi: $10.1177 / 109442810141004$

Chess, S. \& Shaw, A. (2015). A conspiracy of fishes, or, how we learned to stop worrying about \#GamerGate and embrace hegemonic masculinity. Journal of Broadcasting \& Electronic Media, 59(1), 208-220. doi:

$10.1080 / 08838151.2014 .999917$ 
Cruea, M. \& Park, S. (2012). Gender disparity in video game usage: A third-person perception-based explanation. Media Psychology, 15, 44-67. doi: $10.1080 / 15213269.2011 .648861$

Dockterman, E. (2014). What is \#GamerGate and why are women being threatened about video games? Time. Retrieved from: http://time.com/3510381/gamergatefaq/

Eagly, A.H. \& Carli, L.L. (2003). The female leadership advantage: An evaluation of the evidence. The Leadership Quarterly, 14, 807-834. doi: 10.1016/j.leaqua.2003.09.004

Halbertsam, J. (2002). An introduction to female masculinity: Masculinity without men. The Masculinity Studies Reader, 355-374.

Hall, J., \& Braunwald, K.G. (1981). Gender cues in conversations. Journal of Personality and Social Psychology, 40(1), 99-110.

Howard, T. (2015). Fallout 4 [Video game]. Rockville, MD: Bethesda Game Studios.

Jenson, J. \& de Castell, S. (2011). Girls@play: An ethnographic study of gender and digital gameplay. Feminist Media Studies, 11(2), 167-179. doi: $10.1080 / 14680777.2010 .521625$

Kang, M. (2010). Measuring social media credibility: A study on a measure of blog credibility. Retrieved from: http://www.instituteforpr.org/measuring-blogcredibility

Kimmel, M.S. (2004). Masculinity as homophobia: Fear, shame, and silence in the 
construction of gender identity. In Race, Class, and Gender in the United States: An Integrated Study. P.S. Rothenberg (Ed.) New York: Worth, 81-93.

Knobloch-Westerwick, S. \& Hoplamazian, G.J. (2012). Gendering the self: Selective magazine reading and reinforcement of gender conformity. Communication Research, 39(3), 358-384. doi: 10.1177/0093650211425040

Krahulik, M. \& Holkins, J. (2010). The sixth slave. Penny Arcade. Retrieved from: http://www.penny-arcade.com/comic/2010/08/11/the-sixth-slave

Linek, S., Gerjets, P., \& Scheiter, K. (2010). The speaker/gender effect: Does the speaker's gender matter when presenting auditory text in multimedia messages? Instructional Science, 38, 503-521. doi: 10.1007/s11251-009-9115-8

Lofgren, K. (2015). 2015 Video game statistics \& trends: Who's playing what \& why? Big Fish Games. Retrieved from: http://www.bigfishgames.com/blog/2015global-video-game-stats-whos-playing-what-and-why/

Lynch, J. \& Schuler, D. (1994). The matchup effect of spokesperson and product: A schema theory interpretation. Psychology \& Marketing, 11(5), 417-445.

Major, L.H. \& Coleman, R. (2008). The intersection of race and gender in election coverage: What happens when the candidates don't fit stereotypes? The Howard Journal of Communications, 19, 315-333. doi: 10.1080/10646170802391722

Mundorf, N., Dholakia, N., Westin, S., \& Brownell, W. (1992). Reevaluating gender differences in new communication technologies. Communication Research Reports, 9(2), 171-181. 
Ohanian, R. (1990). Construction and validation of a scale to measure celebrity endorsers' perceived expertise, trustworthiness, and attractiveness. Journal of Advertising, 19(3), 39-52.

Phillips, S. J., \& Lord, R. G. (1982). Schematic information processing and perceptions of leadership in problem-solving groups. Journal of Applied Psychology, 67(4), 486-492.

Pulos, A. (2013). Confronting heteronormativity in online games: A critical discourse analysis of LGBTQ sexuality in World of Warcraft. Games and Culture, 8(2), 7797. doi: $10.1177 / 1555412013478688$

Royse, P., Lee, J., Undrahbuyan, B., Hopson, M., \& Consalvo, M. (2007). Women and games: Technologies of the gendered self. New Media \& Society, 9(4), 555-576. doi: $10.1177 / 1461444807080322$

Salter, A., \& Blodgett, B. (2012). Hypermasculinity and Dickwolves: The contentious role of women in the new gaming public. Journal of Broadcasting \& Electronic Media, 56(3), 401-416. doi: 10.1080/08838151.2012.705199

Schippers, M. (2007). Recovering the feminine other: Masculinity, femininity, and gender hegemony. Theory and Society, 36, 85-102. doi: 10.1007/s11186-007$9022-4$

Sellnow, D.D., \& Treinen, K.P. (2004). The role of gender in perceived speaker competence: An analysis of student peer critiques. Communication Education, 53(3), 286-296. doi: 10.1080/0363452042000265215 
Shen, C., Ratan, R., Cai, Y.D., \& Leavitt, A. (2016). Do men advance faster than women? Debunking the gender performance gap in two massively multiplayer online games. Journal of Computer-Mediated Communication, 1-18. doi: $10.1111 /$ jcc 4.12159

Strach, P., Zuber, K., Fawler, E.F., Ridout, T.N., \& Searles, K. (2015). In a different voice? Explaining the use of men and women as voice-over announcers in political advertising. Political Communication, 32(2), 183-205. doi: $10.1080 / 10584609.2014 .914614$

Thornham, H. (2008). It's a boy thing: Gaming, gender, and geeks. Feminist Media Studies, 8(2), 127-142. doi: 10.1080/14680770801980505

Tversky, A. \& Kahneman, D. (1974). Judgment under uncertainty: Heuristics and biases. Science, 185(4157), 1124-1131.

West, C. \& Zimmerman, D.H. (1987). Doing gender. Gender \& Society, 2(1), 125-151. doi: $10.1177 / 0891243287001002002$

Williams, D., Caplan, S., \& Xiong, L. (2007). Can you hear me now? The impact of voice in an online gaming community. Human Communication Research, 33, 427-449. doi: 10.1111/j.1468-2958.2007.00306

Williams, D., Consalvo, M., Caplan, S., \& Yee, N. (2009). Looking for gender: Gender roles and behaviors among online gamers. Journal of Communication, 59, 700725. doi: $10.1111 / \mathrm{j} .1460-2466.2009$ 
Withers, A. (2015, November 20). Meet the Top Female Streamers on Twitch. [Video file]. Retrieved from: www.bloomberg.com/news/videos/2015-11-20/meet-thetop-female-streamers-on-twitch

Yates, S.J., \& Littleton, K. (1999). Understanding computer game cultures: A situated approach. Communication \& Society, 2(4), 566-583. doi:

$10.1080 / 136911899359556$ 


\section{Appendix A: Recruitment Script}

My name is Robin Crowell, and I am a graduate student at Portland State University. I am beginning a study about video gaming communication technologies, and I would like to invite you to participate.

Participants in this study should be video gamers who are 18 years of age or older with a positive Mechanical Turk rating. As part of the study, I am interested in your opinions and attitudes about video game tutorials, and my hope is that your participation will increase knowledge for the future. If you decide to participate, you will be asked to complete an online survey. You will watch a short video game tutorial and then respond to questions about the video. The survey should take you 20 minutes or less.

You will be credited 20 cents to your Amazon Mechanical Turk account as compensation for your participation in the study. To participate, you must be a video gamer and be 18 years of age or older. Additionally, you must have audio and video capabilities at your disposal.

There are minimal risks associated with participating, as you might feel uncomfortable sharing information about yourself, and from watching a short video game tutorial featuring mild violent content. Overall, the risks associated with this study are less than one would experience in everyday life. The study may help to increase knowledge that may help others in the future. In exchange for your participation, you will receive 20 cents credited to your Mechanical Turk account.

Your identity will be kept confidential and your participation is voluntary. You may quit at any time, and you may refuse to answer any questions on the survey. Your decision to participate or not will not affect your relationship with the researcher or with Portland State University in any way.

If you have questions or concerns about your participation in this study, contact Robin Crowell at robin22@pdx.edu or Lauren Frank at 1frank@pdx.edu. If you have concerns about your rights as a research subject, please contact Research and Strategic Partnerships, Market Center Building $6^{\text {th }}$ floor, Portland State University, (503) 725-4288.

Thank you for your time. Your participation is greatly appreciated.

Sincerely, Robin Crowell M.A. Candidate Portland State University 


\section{Appendix B: Stimulus Script}

Here we are in the Museum of Witchcraft in Salem. I received a side quest to come over here and check things out. The quest is called the Devil's Due. [0:00 - 0:11; pause]

Now I'm going through (PAUSE) looting and exploring everything - this is a particularly unnerving location in Fallout 4, so it's one that you will want to spend more time in to take in all the sights. [0:22-0:33]

There's a savage deathclaw here: one of Fallout's most formidable foes. Now I just fell through the floor so I'll have to get back over there by taking the stairs. That was a little disorienting. [0:39-0:52]

The last time I did this (PAUSE) the deathclaw came and attacked me from across the room as soon as I reached the top of the stairs. This time I've got a Molotov cocktail on him to layer some damage on him-let's see how far I can push him before he lunges at me. [0:53-1:09]

[PAUSE]

Notice how he does nothing. Even after another Molotov? Here I am pinging him and he just stands there? That's disappointing. [1:12 - 1:18]

[PAUSE while opening Pip-Boy]

Alright, it's time to push the limits here. (PAUSE) I'm about to equip the fat man and see how much he stands around. Need to be careful here not to kill myself because we're working with a FAIRLY confined space here. [pause] Alright, let's move and get into position. Oh NOW he decides to come after me. [1:23 - 1:39]

Moving into position... (PAUSE) Don't want to get too close (PAUSE) mini nuke to the face! and he's still not dead? [1:38 - 1:45]

Guess I'll switch back here and ping him to death. (PAUSE) Not much more to go.

(PAUSE) THERE WE GO -he's TOAST. [1:46 - 1:51]

NOW Go through, explore the rest of this place and wrap up this quest. (PAUSE) Don't forget to grab some loot. [1:55 -2:03]

[PAUSE 2:03 - 2:09]

So now you've gotta go in and get rid of these deathclaw eggs here and you'll find a holotape, listen to it, and. You'll get to choose what to do with the deathclaw eggs but first, I'm going to pick up the rest of this loot. [2:10 - 2:18]

[cut at 2:30] 


\section{Appendix C: Survey Instrument}

\section{Consent}

You are invited to participate in a research study conducted by Robin Crowell under the direction of Dr. Frank. This study attempts to collect information about video gaming culture. You were selected as a possible participant in this study because you play video games and have a positive rating on Mechanical Turk.

\section{Procedures}

If you decide to participate, you will be asked to watch a short video and complete the following questionnaire. The questionnaire will take approximately 20 minutes or less. Please make sure that you have audio and video capabilities, and that your volume is turned up or your headphones are plugged in.

\section{Risks/Discomforts}

Risks are minimal for involvement in this study. However, you may feel uncomfortable when asked to share demographic information about yourself and watching a mildly violent video. You are welcome to skip any question that you feel uncomfortable answering.

\section{Benefits}

You may not receive any direct benefit from taking part in this study. However, it is hoped that through your participation, the study may help to increase knowledge which may help others in the future.

\section{Confidentiality}

All information that is obtained in connection with this study will be kept confidential and will only be reported in an aggregate format (by reporting only combined results and never reporting individual ones). All questionnaires will be concealed, and no one other 
than the research team will have access to them. At no point will your name be linked to your answers.

\section{Compensation}

For completing this survey, you will receive 20 cents as compensation to your Mechanical Turk account.

\section{Participation}

Participation in this research study is completely voluntary. You have the right to withdraw at any time or refuse to participate entirely.

\section{Questions about the Research}

If you have questions or concerns regarding this study, contact Robin Crowell at robin22@pdx.edu or Dr. Frank at 1frank@pdx.edu.

\section{Questions about your Rights as Research Participants}

If you have questions or concerns about your rights as a research subject, please contact Research and Strategic Partnerships, Market Center Building 6th floor, Portland State University, 503-725-4288. By completing this survey, you are certifying that you are 18 years of age or older, that you have read and understand the above information and agree to take part in the survey. To print this consent form on PC, press CTRL + P. To print this consent form on Mac, press COMMAND + P.

If at this point you choose to continue in this research study, please click "I consent" to continue.

\section{O I Consent}

Please answer the following questions honestly and to the best of your ability.

Do you play video games?
O Yes
No

If Yes Is Selected, Then Skip To About how many hours per week do you ...If No Is Selected, Then Skip To Do you use media applications like Tw...

About how many hours per week do you spend playing video games? 
Do you use media applications like Twitch, YouTube Gaming, or online game tutorials?

O Yes

O No

If Yes Is Selected, Then Skip To How many hours per day on average wou...If No Is

Selected, Then Skip To End of Block

How many hours per day on average would you say that you use media applications like Twitch, YouTube Gaming, or online game tutorials?

Please watch the following video and be prepared to answer questions about it after it ends. Ensure that your volume is up or your headphones are plugged in.

[Male voiced video] Please watch the following walkthrough video from Fallout 4.

[Female voiced video] Please watch the following walkthrough video from Fallout 4.

Please answer the following questions to the best of your ability. 
Please indicate the level to which you agree with the following statements: 


\begin{tabular}{|c|c|c|c|c|c|}
\hline & $\begin{array}{c}\text { Strongly } \\
\text { Disagree (1) }\end{array}$ & $\begin{array}{c}\text { Disagree } \\
\text { (2) }\end{array}$ & $\begin{array}{c}\text { Neither } \\
\text { Agree nor } \\
\text { Disagree } \\
\text { (3) }\end{array}$ & Agree (4) & $\begin{array}{c}\text { Strongly } \\
\text { Agree (5) }\end{array}$ \\
\hline $\begin{array}{l}\text { The player } \\
\text { was able to } \\
\text { achieve the } \\
\text { goals they } \\
\text { set out to } \\
\text { accomplish. }\end{array}$ & O & 0 & 0 & O & O \\
\hline $\begin{array}{l}\text { When facing } \\
\text { difficult } \\
\text { tasks, the } \\
\text { player } \\
\text { seemed } \\
\text { certain in } \\
\text { being able to } \\
\text { accomplish } \\
\text { them. }\end{array}$ & $\mathrm{O}$ & $\mathrm{O}$ & $\mathrm{O}$ & O & O \\
\hline $\begin{array}{l}\text { In general, } \\
\text { the player } \\
\text { could obtain } \\
\text { desirable } \\
\text { outcomes in } \\
\text { many game } \\
\text { situations. }\end{array}$ & O & $\mathrm{O}$ & O & O & O \\
\hline $\begin{array}{l}\text { I believe the } \\
\text { player could } \\
\text { achieve any } \\
\text { in-game } \\
\text { goals that } \\
\text { they set their } \\
\text { mind to. }\end{array}$ & O & 0 & O & O & O \\
\hline $\begin{array}{l}\text { The player } \\
\text { will be able } \\
\text { to } \\
\text { successfully } \\
\text { overcome in- } \\
\text { game } \\
\text { challenges. }\end{array}$ & 0 & 0 & 0 & 0 & 0 \\
\hline
\end{tabular}




\begin{tabular}{|c|c|c|c|c|}
\hline $\begin{array}{c}\text { I am } \\
\text { confident } \\
\text { that the } \\
\text { player can } \\
\text { effectively } \\
\text { perform on } \\
\text { many } \\
\text { different }\end{array}$ & 0 & 0 & 0 & 0 \\
game-related \\
tasks. \\
$\begin{array}{c}\text { Compared to } \\
\text { other people, } \\
\text { the player } \\
\text { can do most } \\
\text { in-game } \\
\text { tasks very } \\
\text { well. }\end{array}$
\end{tabular}

Please indicate the level to which you agree with the following statements. 


\begin{tabular}{|c|c|c|c|c|c|}
\hline & $\begin{array}{c}\text { Strongly } \\
\text { Disagree } \\
\text { (1) }\end{array}$ & $\begin{array}{l}\text { Disagree } \\
\text { (2) }\end{array}$ & $\begin{array}{c}\text { Neither } \\
\text { Agree nor } \\
\text { Disagree } \\
(3)\end{array}$ & Agree (4) & $\begin{array}{c}\text { Strongly } \\
\text { Agree (5) }\end{array}$ \\
\hline $\begin{array}{l}\text { I could ask } \\
\text { the speaker in } \\
\text { the video for } \\
\text { more } \\
\text { information } \\
\text { about the } \\
\text { game. }\end{array}$ & O & O & $\mathrm{O}$ & O & O \\
\hline $\begin{array}{l}\text { If the speaker } \\
\text { did not know } \\
\text { the answer to } \\
\text { a question } \\
\text { about the } \\
\text { game, they } \\
\text { would know } \\
\text { where to look } \\
\text { to find the } \\
\text { answer. }\end{array}$ & 0 & O & 0 & O & O \\
\hline $\begin{array}{l}\text { The speaker } \\
\text { was } \\
\text { confident in } \\
\text { their } \\
\text { approach to } \\
\text { relaying } \\
\text { information. }\end{array}$ & 0 & 0 & 0 & 0 & O \\
\hline $\begin{array}{l}\text { While } \\
\text { playing, the } \\
\text { speaker knew } \\
\text { how to solve } \\
\text { problems. }\end{array}$ & 0 & O & 0 & 0 & O \\
\hline $\begin{array}{l}\text { The player's } \\
\text { skills showed } \\
\text { a knowledge } \\
\text { of how to } \\
\text { obtain } \\
\text { important in- } \\
\text { game } \\
\text { information }\end{array}$ & O & O & $\mathrm{O}$ & O & O \\
\hline
\end{tabular}




\begin{tabular}{|c|c|c|c|c|c|}
\hline $\begin{array}{l}\text { I doubted } \\
\text { some of the } \\
\text { player's in- } \\
\text { game } \\
\text { choices. } \\
\text { The player } \\
\text { seemed } \\
\text { apologetic } \\
\text { when making } \\
\text { in-game } \\
\text { errors. }\end{array}$ & 0 & 0 & 0 & 0 & 0 \\
\hline $\begin{array}{l}\text { I questioned } \\
\text { the player's } \\
\text { in-game } \\
\text { actions. }\end{array}$ & 0 & 0 & 0 & 0 & 0 \\
\hline $\begin{array}{l}\text { The player } \\
\text { seemed to be } \\
\text { doing the } \\
\text { wrong things } \\
\text { to meet in- } \\
\text { game goals. }\end{array}$ & 0 & 0 & 0 & 0 & 0 \\
\hline $\begin{array}{l}\text { The speaker } \\
\text { seemed } \\
\text { dissatisfied } \\
\text { with their } \\
\text { performance. }\end{array}$ & 0 & 0 & 0 & 0 & 0 \\
\hline $\begin{array}{l}\text { I was } \\
\text { impressed } \\
\text { with the level } \\
\text { of in-game } \\
\text { confidence } \\
\text { the speaker } \\
\text { showed. }\end{array}$ & 0 & 0 & 0 & 0 & 0 \\
\hline $\begin{array}{l}\text { I was } \\
\text { impressed by } \\
\text { the speaker's } \\
\text { decisions. }\end{array}$ & 0 & 0 & 0 & 0 & 0 \\
\hline $\begin{array}{l}\text { I admire the } \\
\text { speaker's in- } \\
\text { game } \\
\text { abilities. }\end{array}$ & 0 & 0 & 0 & 0 & 0 \\
\hline
\end{tabular}




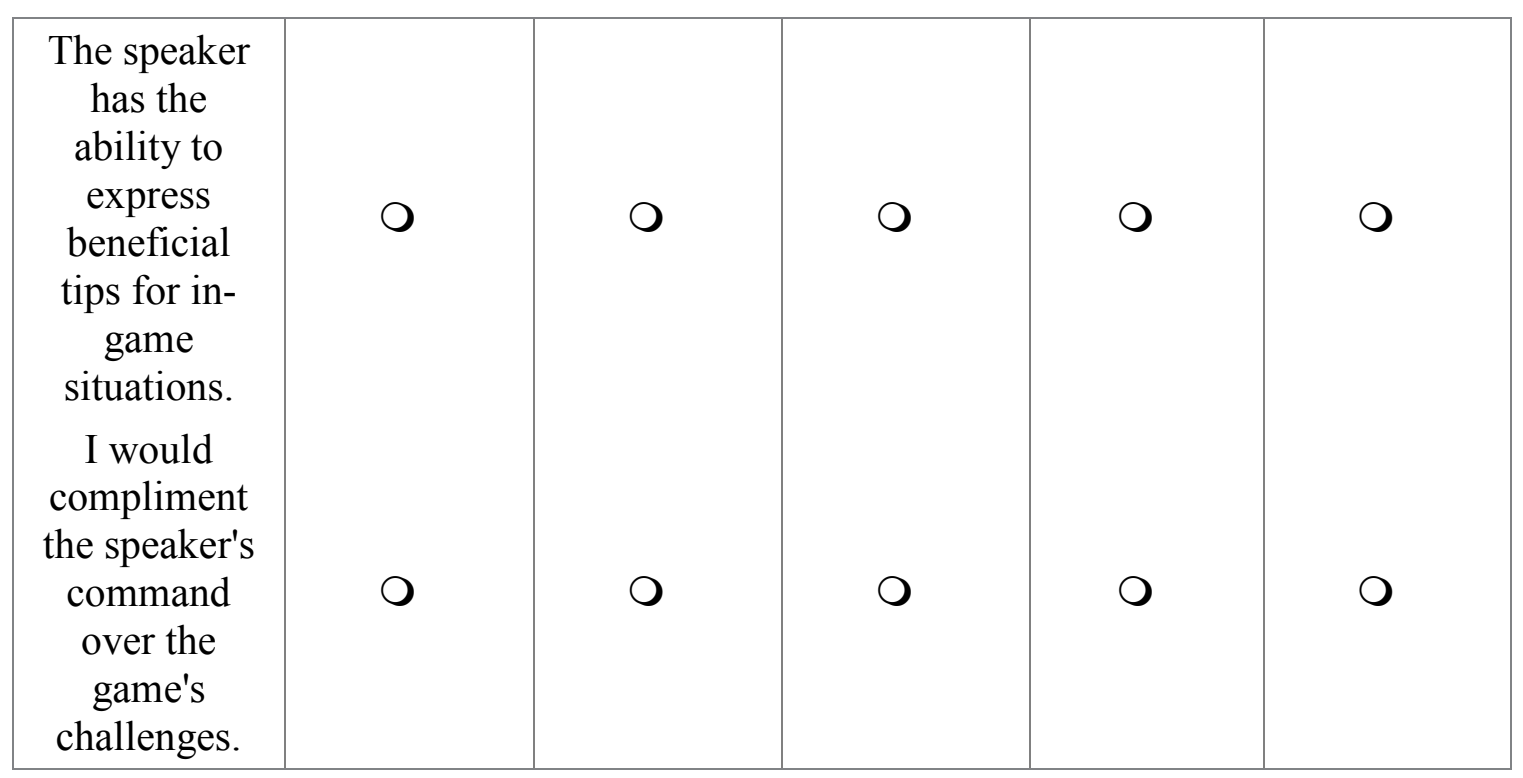

I believe the speaker in the video is:

\begin{tabular}{|c|c|c|c|c|c|}
\hline & $\begin{array}{c}\text { Strongly } \\
\text { Disagree } \\
(1)\end{array}$ & $\begin{array}{c}\text { Disagree } \\
(2)\end{array}$ & $\begin{array}{c}\text { Neither } \\
\text { Agree nor } \\
\text { Disagree } \\
(3)\end{array}$ & Agree (4) & $\begin{array}{c}\text { Strongly } \\
\text { Agree (5) }\end{array}$ \\
\hline Knowledgeable & 0 & 0 & 0 & 0 & 0 \\
Influential & 0 & 0 & 0 & 0 & 0 \\
Passionate & 0 & 0 & 0 & 0 & 0 \\
Transparent & 0 & 0 & 0 & 0 & 0 \\
Reliable & 0 & 0 & 0 & 0 & 0 \\
\hline
\end{tabular}


I believe the information in the video is:

\begin{tabular}{|c|c|c|c|c|c|}
\hline & $\begin{array}{c}\text { Strongly } \\
\text { Disagree } \\
(1)\end{array}$ & $\begin{array}{c}\text { Disagree } \\
(2)\end{array}$ & $\begin{array}{c}\text { Neither } \\
\text { Agree nor } \\
\text { Disagree }\end{array}$ & Agree (4) & $\begin{array}{c}\text { Strongly } \\
\text { Agree (5) }\end{array}$ \\
\hline Authentic & 0 & 0 & 0 & 0 & 0 \\
Insightful & 0 & 0 & 0 & 0 & 0 \\
Informative & 0 & 0 & 0 & 0 & 0 \\
Consistent & 0 & 0 & 0 & 0 & 0 \\
Fair & 0 & 0 & 0 & 0 & 0 \\
Focused & 0 & 0 & 0 & 0 & 0 \\
Accurate & 0 & 0 & 0 & 0 & 0 \\
Timely & 0 & 0 & 0 & 0 & 0 \\
Popular & 0 & 0 & 0 & 0 & 0 \\
\hline
\end{tabular}

Please indicate the level to which you agree with the following statements. 


\begin{tabular}{|c|c|c|c|c|c|}
\hline & $\begin{array}{c}\text { Strongly } \\
\text { Disagree } \\
\text { (1) (1) }\end{array}$ & $\begin{array}{c}\text { Disagree } \\
\text { (2) (2) }\end{array}$ & $\begin{array}{l}\text { Neither } \\
\text { Agree nor } \\
\text { Disagree } \\
\text { (3) (3) }\end{array}$ & $\begin{array}{c}\text { Agree (4) } \\
\text { (4) }\end{array}$ & $\begin{array}{l}\text { Strongly } \\
\text { Agree (5) } \\
\quad(5)\end{array}$ \\
\hline $\begin{array}{l}\text { The player } \\
\text { was willing to } \\
\text { admit when } \\
\text { they made a } \\
\text { mistake. (1) }\end{array}$ & 0 & 0 & 0 & 0 & 0 \\
\hline $\begin{array}{l}\text { The player set } \\
\text { specific goals } \\
\text { for the } \\
\text { tutorial. (2) }\end{array}$ & 0 & 0 & 0 & 0 & 0 \\
\hline $\begin{array}{l}\text { The player } \\
\text { delayed acting } \\
\text { in certain } \\
\text { circumstances. } \\
\text { (3) }\end{array}$ & 0 & 0 & 0 & 0 & 0 \\
\hline $\begin{array}{c}\text { I trust the } \\
\text { player's } \\
\text { judgment. (4) }\end{array}$ & 0 & 0 & 0 & 0 & 0 \\
\hline $\begin{array}{l}\text { The player } \\
\text { maintained } \\
\text { manageable } \\
\text { performance } \\
\text { standards. (5) }\end{array}$ & 0 & 0 & 0 & 0 & 0 \\
\hline $\begin{array}{l}\text { The player } \\
\text { expressed } \\
\text { confusion } \\
\text { about the in- } \\
\text { game tasks. } \\
\text { (6) }\end{array}$ & 0 & 0 & 0 & 0 & 0 \\
\hline $\begin{array}{l}\text { The player did } \\
\text { things without } \\
\text { explaining } \\
\text { their actions. } \\
\text { (7) }\end{array}$ & 0 & 0 & 0 & 0 & 0 \\
\hline $\begin{array}{l}\text { The details of } \\
\text { the task } \\
\text { seemed to } \\
\text { overwhelm } \\
\text { the player. ( } 8)\end{array}$ & 0 & 0 & 0 & 0 & 0 \\
\hline
\end{tabular}




\begin{tabular}{|c|c|c|c|c|c|}
\hline $\begin{array}{c}\text { The player } \\
\text { suggested } \\
\text { poor solutions } \\
\text { to in-game } \\
\text { tasks. (9) }\end{array}$ & 0 & 0 & 0 & 0 & 0 \\
$\begin{array}{c}\text { The player is a } \\
\text { good }\end{array}$ & 0 & 0 & 0 & 0 & 0 \\
$\begin{array}{c}\text { spokesperson } \\
\text { for the topic. } \\
\text { (10) }\end{array}$ & 0 & 0 &
\end{tabular}

I think that the speaker in the video was...

\begin{tabular}{|c|c|c|c|c|c|}
\hline & 1 & 2 & 3 & 4 & 5 \\
\hline Undependable:Dependable & 0 & 0 & 0 & 0 & 0 \\
Dishonest:Honest & 0 & 0 & 0 & 0 & 0 \\
Unreliable:Reliable & 0 & 0 & 0 & 0 & 0 \\
Deceitful:Sincere & 0 & 0 & 0 & 0 & 0 \\
Untrustworthy:Trustworthy & 0 & 0 & 0 & 0 & 0 \\
\hline
\end{tabular}


Please answer the following questions.

\begin{tabular}{|c|c|c|c|c|c|}
\hline & $\begin{array}{c}\text { Very } \\
\text { Masculine } \\
\text { (1) }\end{array}$ & $\begin{array}{c}\text { Masculine } \\
\text { (2) }\end{array}$ & $\begin{array}{c}\text { Neither } \\
\text { Masculine } \\
\text { nor } \\
\text { Feminine } \\
\text { (3) }\end{array}$ & $\begin{array}{c}\text { Feminine } \\
\text { (4) }\end{array}$ & $\begin{array}{c}\text { Very } \\
\text { Feminine } \\
(5)\end{array}$ \\
\hline $\begin{array}{c}\text { I feel as } \\
\text { though I } \\
\text { am... }\end{array}$ & 0 & 0 & 0 & 0 & $\bigcirc$ \\
\hline $\begin{array}{c}\text { I look as } \\
\text { though I } \\
\text { am... }\end{array}$ & 0 & 0 & 0 & 0 & 0 \\
\hline $\begin{array}{l}\text { I do most } \\
\text { things in a } \\
\text { manner } \\
\text { typical of } \\
\text { someone } \\
\text { who is... }\end{array}$ & 0 & 0 & 0 & 0 & 0 \\
\hline $\begin{array}{c}\text { My } \\
\text { interests are } \\
\text { mostly } \\
\text { those of a } \\
\text { person who } \\
\text { is... }\end{array}$ & 0 & 0 & 0 & 0 & 0 \\
\hline
\end{tabular}

Please answer the following demographic questions honestly and to the best of your ability.

What was the gender of the speaker in the gameplay video tutorial?
O Male
O Female 
What is your gender?
O Male
O Female
Other

Age In what year were you born?
○ 1921
○ 1922
○ 1923
○ 1924
○ 1925
○ 1926
○ 1927
○ ...
○ 1990
○ 1991
○ 1992
○ 1993
○ 1994
○ 1995
○ 1996
○ 1997
○ 1998
○ 1999

Do you identify as a gamer?
O Yes
No 
Please indicate how often you play the following video game genres. 


\begin{tabular}{|c|c|c|c|c|c|}
\hline & Never (1) & Rarely (2) & $\begin{array}{c}\text { Sometimes } \\
\text { (3) }\end{array}$ & Often (4) & Always (5) \\
\hline $\begin{array}{c}\text { First-Person } \\
\text { Shooter } \\
\text { (Halo, Call } \\
\text { of Duty, etc.) }\end{array}$ & $\mathrm{O}$ & $\mathrm{O}$ & $\mathrm{O}$ & $\mathrm{O}$ & $\mathrm{O}$ \\
\hline $\begin{array}{c}\text { Role-Playing } \\
\text { Game (RPG) } \\
\text { (Fallout 4, } \\
\text { The Elder } \\
\text { Scrolls V: } \\
\text { Skyrim, etc) }\end{array}$ & O & $\mathrm{O}$ & $\mathrm{O}$ & $\mathrm{O}$ & $\mathrm{O}$ \\
\hline $\begin{array}{l}\text { Third-Person } \\
\text { Adventure } \\
\text { (Assassin's } \\
\text { Creed, Mass } \\
\text { Effect, etc.) }\end{array}$ & O & 0 & 0 & 0 & 0 \\
\hline $\begin{array}{c}\text { Survival } \\
\text { Horror } \\
\text { (Resident } \\
\text { Evil, Dead } \\
\text { Space, etc.) }\end{array}$ & $\mathrm{O}$ & 0 & $\mathrm{O}$ & $\mathrm{O}$ & 0 \\
\hline $\begin{array}{c}\text { Creative } \\
\text { (Minecraft, } \\
\text { Project } \\
\text { Spark, etc.) }\end{array}$ & 0 & 0 & 0 & $\mathrm{O}$ & $\mathrm{O}$ \\
\hline $\begin{array}{c}\text { MMORPG } \\
\text { (World of } \\
\text { Warcraft, } \\
\text { The Elder } \\
\text { Scrolls } \\
\text { Online: } \\
\text { Tamriel } \\
\text { Unlimited, } \\
\text { etc.) }\end{array}$ & 0 & 0 & $\mathrm{O}$ & $\mathrm{O}$ & 0 \\
\hline $\begin{array}{c}\text { Platformer } \\
\text { (Super Meat } \\
\text { Boy, Sonic } \\
\text { the } \\
\text { Hedgehog, } \\
\text { etc.) }\end{array}$ & 0 & 0 & $\mathrm{O}$ & $\mathrm{O}$ & 0 \\
\hline
\end{tabular}




\begin{tabular}{|c|c|c|c|c|c|}
\hline $\begin{array}{l}\text { Racing } \\
\text { (Forza, Gran } \\
\text { Turismo, } \\
\text { etc.) }\end{array}$ & 0 & 0 & 0 & 0 & 0 \\
\hline $\begin{array}{c}\text { Sports } \\
\text { (Madden } \\
\text { NFL, FIFA, } \\
\text { etc.) }\end{array}$ & 0 & 0 & $\bigcirc$ & 0 & $\bigcirc$ \\
\hline $\begin{array}{c}\text { Other. Please } \\
\text { specify } \\
\text { below. }\end{array}$ & 0 & 0 & 0 & 0 & 0 \\
\hline
\end{tabular}

Other game types played.

Have you ever played Fallout 4 ?

Y Yes

No 